\title{
Optical and structural properties of biological tissues under diabetes mellitus
}

\author{
Daria K. Tuchina ${ }^{1,2^{*}}$ and Valery V. Tuchin ${ }^{1,3,4}$ \\ ${ }^{1}$ Saratov State University, 83 Astrakhanskaya Str., Saratov 410012, Russia \\ 2 Tomsk State University, 36 Prosp. Lenina, Tomsk 634050, Russia \\ ${ }^{3}$ Samara National Research University, 34 Moskovskoye Shosse, Samara 443086, Russia \\ ${ }^{4}$ Laboratory of Laser Diagnostics of Technical and Living Systems, Institute of Precision Mechanics and Control, \\ Russian Academy of Sciences, 24 Rabochaya Str., Saratov 410028, Russia \\ *e-mail: tuchinadk@mail.ru
}

\begin{abstract}
Diabetes mellitus is a serious social and economic problem of modern society because it is widespread and fraught with numerous complications. Therefore, it is necessary to search for new methods of diabetes mellitus diagnostics and treatment and to improve the existing ones, which, in turn, requires thorough investigation of the disease development mechanisms, as well as elaboration of simple and reliable methods and criteria for detecting the complication precursors. In connection with the solution of these problems, in the paper we present an analytical review of recent publications devoted to the study of the changes of structural and optical properties of biological tissues under the conditions of diabetes mellitus development using in vitro models of glycated tissues, in vivo experimental models of diabetes in laboratory animals, and clinical studies. (C) 2018 Journal of Biomedical Photonics \& Engineering.
\end{abstract}

Keywords: diabetes mellitus; protein glycation; tissues; skin; myocardium; cardiovascular system; optical properties; diffusion of metabolites.

Paper \#3284 received 14 Mar 2018; revised manuscript received 16 May 2018; accepted for publication 11 Jun 2018; published online 29 Jun 2018. doi: 10.18287/JBPE18.04.020201.

\section{References}

1. J. E. Shaw, R. A. Sicree, and P. Z. Zimmet, "Global estimates of the prevalence of diabetes for 2010 and 2030," Diabetes Research and Clinical Practice 87, 4-14 (2010).

2. Diabetes Fact Sheet, World Health Organization (2017).

3. C. D. Mathers, D. Loncar, "Projections of Global Mortality and Burden of Disease from 2002 to 2030," PLoS Medicine 3(11), e442 (2006).

4. D. LeRoith, S. I. Taylor, and J. M. Olefsky (Eds.), Diabetes Mellitus: A Fundamental and Clinical Text, 3rd edition, Lippincott Williams \& Wilkins (2004).

5. K. T. Patton, G. A. Thibodeau, The Human Body in Health \& Disease, 6th Edition, Elsevier Inc. (2014).

6. D. G. Gardner, D. M. Shoback, Greenspan's Basic \& Clinical Endocrinology, 9th Edition, McGraw-Hill Medical, NY (2011).

7. B. B. Tripathy, RSSDI Textbook of Diabetes Mellitus, 2nd Edition, Jaypee Brothers Medical Publishers, New Delhi (2012).

8. Diabetes Care, Volume 40, Supplement 1, American Diabetes Association Inc. (2017).

9. A. J. King, "The use of animal models in diabetes research," British Journal of Pharmacology 166, 877-894 (2012).

10. T. Szkudelski, "The mechanism of alloxan and streptozotocin action in B cells of the rat pancreas," Physiological Research 50(6), 537-546 (2001).

11. S. Lenzen, "The mechanisms of alloxan- and streptozotocin-induced diabetes," Diabetologia 51, 216-226 (2008).

12. A. Burgeiro, A. Fuhrmann, S. Cherian, D. Espinoza, I. Jarak, R. A. Carvalho, M. Loureiro, M. Patrício, M. Antunes, and E. Carvalho, "Glucose uptake and lipid metabolism are impaired in epicardial adipose tissue 
from heart failure patients with or without diabetes," American Journal of Physiology-Endocrinology and Metabolism 310(7), E550-E564 (2016).

13. V. Vinokur, G. Leibowitz, L. Grinberg, R. Eliashar, E. Berenshtein, and M. Chevion, "Diabetes and the heart: could the diabetic myocardium be protected by preconditioning?" Redox Report 12(6), 246-256 (2007).

14. T. Nishikawa, D. Edelstein, X. L. Du, S. Yamagishi, T. Matsumura, Y. Kaneda, M. A. Yorek, D. Beebe, P. J. Oates, H. P. Hammes, I. Giardino, and M. Brownlee, "Normalizing mitochondrial superoxide production blocks three pathways of hyperglycemic damage," Nature 404(6779), 787-790 (2000).

15. X. Du, T. Matsumura, D. Edelstein, D. Edelstein, L. Rossetti, Z. Zsengellér, C. Szabó, and M. Brownlee, "Inhibition of GAPDH activity by poly(ADP-ribose) polymerase activates three major pathways of hyperglycemic damage in endothelial cells," Journal of Clinical Investigation 112(7), 1049-1057 (2003).

16. M. Chevion, "A site-specific mechanism for free radical induced biological damage: the essential role of redox-active transition metals," Free Radical Biology and Medicine 5(1), $27-37$ (1988).

17. N. Vigneshwaran, G. Bijukumar, N. Karmakar, S. Anand, and A. Misra, "Autofluorescence characterization of advanced glycation end products of hemoglobin," Spectrochimica Acta Part A: Molecular and Biomolecular Spectroscopy 61(1-2), 163-170, (2005).

18. N. I. Dikht, A. B. Bucharskaya, G. S. Terentyuk, G. N. Maslyakova, O. V. Matveeva, N. A. Navolokin, N. G. Khlebtsov, and B. N. Khlebtsov, "Morphological study of the internal organs in rats with alloxan diabetes and transplanted liver tumor after intravenous injectin of gold nanorods," Russian Open Medical Journal 3(3), 0301 (2014).

19. D. McGuire, N. Marx, Diabetes in Cardiovascular Disease: A Companion to Braunwald's Heart Disease, Elsevier Health Sciences (2014).

20. V. V. Tuchin (Ed.), Handbook of Optical Sensing of Glucose in Biological Fluids and Tissues, Taylor \& Francis Group LLC, CRC Press (2009).

21. H. Ullah, A. Mariampillai, M. Ikram, and I. A. Vitkin, "Can Temporal Analysis of Optical Coherence Tomography Statistics Report on Dextrorotatory-Glucose Levels in Blood?” Laser Physics 21(11), 1962-1971 (2011).

22. G. Purvinis, B. D. Cameron, and D. M. Altrogge, "Noninvasive polarimetric-based glucose monitoring: an in vivo study," Journal of Diabetes Science and Technology 5(2), 380-387 (2011).

23. N. C. Dingari, I. Barman, G. P. Singh, J. W. Kang, R. R. Dasari, and M. S. Feld, "Investigation of the specificity of Raman spectroscopy in non-invasive blood glucose measurements," Analytical and Bioanalytical Chemistry 400(9), 2871-2880 (2011).

24. Y. Zhang, G. Wu, H. Wei, Z. Guo, H. Yang, Y. He, S. Xie, and Y. Liu, "Continuous noninvasive monitoring of changes in human skin optical properties during oral intake of different sugars with optical coherence tomography," Biomedical Optics Express 5(4), 990-999 (2014).

25. R. Y. He, H. J. Wei, H. M. Gu, Z. G. Zhu, Y. Q. Zhang, X. Guo, and T. Cai, "Effects of optical clearing agents on noninvasive blood glucose monitoring with optical coherence tomography: a pilot study," Journal of Biomedical Optics 17(10), 101513 (2012).

26. M. A. Pleitez, T. Lieblein, A. Bauer, O. Hertzberg, H. von Lilienfeld-Toal, and W. Mäntele, "Windowless ultrasound photoacoustic cell for in vivo mid-IR spectroscopy of human epidermis: Low interference by changes of air pressure, temperature, and humidity caused by skin contact opens the possibility for a noninvasive monitoring of glucose in the interstitial fluid," Review of Scientific Instruments 84(8), 084901 (2013).

27. N. C. Dingari, I. Barman, J. W. Kang, C. R. Kong, R. R. Dasari, and M. S. Feld, "Wavelength selection-based nonlinear calibration for transcutaneous blood glucose sensing using Raman spectroscopy," Journal of Biomedical Optics 16(8), 087009 (2011).

28. J. M. Yuen, N. C. Shah, J. T. Walsh, M. R. Glucksberg, and R. P. Van Duyne, "Transcutaneous glucose sensing by surface-enhanced spatially offset Raman spectroscopy in a rat model," Analytical Chemistry 82(20), 8382-8385 (2010).

29. S. Firdous, M. Nawaz, M. Ahmed, S. Anwar, A. Rehman, R. Rashid, and A. Mahmood, "Measurement of diabetic sugar concentration in human blood using Raman spectroscopy," Laser physics 22(6), 1090-1094 (2012).

30. X. X. Guo, A. Mandelis, and B. Zinman, "Noninvasive glucose detection in human skin using wavelength modulated differential laser photothermal radiometry," Biomedical Optics Express 3(11), 3012-3021 (2012).

31. S. A. A. Shah, A. Laude, I. Faye, and T. B. Tang, "Automated microaneurysm detection in diabetic retinopathy using curvelet transform," Journal of Biomedical Optics 21(10), 101404 (2016).

32. Y. J. Heo, S. Takeuchi, "Towards smart tattoos: implantable biosensors for continuous glucose monitoring," Advanced Healthcare Materials 2(1), 43-56 (2013).

33. E. Selvin, M. W. Steffes, H. Zhu, K. Matsushita, L. Wagenknecht, J. Pankow, J. Coresh, and F. L. Brancati, "Glycated Hemoglobin, Diabetes, and Cardiovascular Risk in Nondiabetic Adults," The New England Journal of Medicine 362(9), 800-811 (2010). 
34. J.-Y. Tseng, A. A. Ghazaryan, W. Lo, Y.-F. Chen, V. Hovhannisyan, S.-J. Chen, H.-Y. Tan, and C.-Y. Dong, "Multiphoton spectral microscopy for imaging and quantification of tissue glycation," Biomedical Optics Express 2(2), 218-230 (2011).

35. G. Mazarevica, T. Freivalds, and A. Jurka, "Properties of erythrocyte light refraction in diabetic patients," Journal of Biomedical Optics 7(2), 244-247 (2002).

36. J. Blackwell, K. M. Katika, L. Pilon, K. M. Dipple, S. R. Levin, and A. Nouvong, "In vivo time-resolved autofluorescence measurements to test for glycation of human skin," Journal of Biomedical Optics 13(1), 014004 (2008).

37. U. Kanska, J. Boratynski, "Thermal glycation of proteins by D-glucose and D-fructose," Archivum Immunologiae et Therapiae Experimentalis 50(1), 61-66 (2002).

38. O. S. Khalil, "Non-Invasive Glucose Measurement Technologies: An Update from 1999 to the Dawn of the New Millennium," Diabetes Technology \& Therapeutics 6(5), 660-697 (2004).

39. D. K. Tuchina, R. Shi, A. N. Bashkatov, E. A. Genina, D. Zhu, Q. Luo, and V. V. Tuchin, "Ex vivo optical measurements of glucose diffusion kinetics in native and diabetic mouse skin," Journal of Biophotonics 8(4), 332-346 (2015).

40. D. K. Tuchina, A. N. Bashkatov, A. B. Bucharskaya, E. A. Genina, and V. V. Tuchin, "Study of glycerol diffusion in skin and myocardium ex vivo under the conditions of developing alloxan-induced diabetes," Journal of Biomedical Photonics \& Engineering 3(2), 020302 (2017).

41. T. Pan, M. Li, J. Chen, and H. Xue, "Quantification of glycated hemoglobin indicator HbA1c through nearinfrared spectroscopy," Journal of Innovative Optical Health Sciences 7(4), 1350060 (2014).

42. E. Shirshin, O. Cherkasova, T. Tikhonova, E. Berlovskaya, A. Priezzhev, and V. Fadeev, "Native fluorescence spectroscopy of blood plasma of rats with experimental diabetes: identifying fingerprints of glucose-related metabolic pathways," Journal of Biomedical Optics 20(5), 051033 (2015).

43. G. V. Maksimov, O. G. Luneva, N. V. Maksimova, E. Matettuchi, E. A. Medvedev, V. Z. Pashchenko, and A. B. Rubin. "Role of viscosity and permeability of the erythrocyte plasma membrane in changes in oxygenbinding properties of hemoglobin during diabetes mellitus," Bulletin of Experimental Biology and Medicine, 140(5), 510-513 (2005).

44. J. F. Villa-Manríquez, J. Castro-Ramos, F. Gutiérrez-Delgado, M. A. Lopéz-Pacheco, and A. E. VillanuevaLuna, "Raman spectroscopy and PCA-SVM as a non-invasive diagnostic tool to identify and classify qualitatively glycated hemoglobin levels in vivo," Journal of Biophotonics 10(8), 1074-1079 (2016).

45. P. A. Timoshina, A. B. Bucharskaya, D. A. Alexandrov, and V. V. Tuchin, "Study of blood microcirculation of pancreas in rats with alloxan diabetes by Laser Speckle Contrast Imaging," Journal of Biomedical Photonics \& Engineering 3(2), 020301 (2017).

46. F. Wei, S. Rui, and D. Zhu, "Monitoring skin microvascular dysfunction of type 1 diabetic mice using in vivo skin optical clearing," Proceedings of SPIE 10493, 1049310 (2018).

47. O. A. Smolyanskaya, I. J. Schelkanova, M. S. Kulya, E. L. Odlyanitskiy, I. S. Goryachev, A. N. Tcypkin, Y. V. Grachev, Ya. G. Toropova, and V. V. Tuchin, "Glycerol dehydration of native and diabetic animal tissues studied by THz-TDS and NMR methods," Biomedical optics express 9(3), 1198 (2018).

48. V. V. Tuchin, Optical Clearing of Tissues and Blood, PM 154, SPIE Press, Bellingham, WA (2006).

49. D. Zhu, K. V. Larin, Q. Luo, and V. V. Tuchin, "Recent progress in tissue optical clearing," Laser \& Photonics Reviews 7(5), 732-757 (2013).

50. L. M. Oliveira, M. I. Carvalho, E. Nogueira, and V. V. Tuchin, "The characteristic time of glucose diffusion measured for muscle tissue at optical clearing," Laser Physics 23(7), 075606 (2013).

51. L. Oliveira, M. I. Carvalho, E. Nogueira, and V. V. Tuchin, "Optical measurement of rat muscle samples under treatment with ethylene glycol and glucose," Journal of Innovative Optical Health Sciences 6(2), 1350012 (2013).

52. M. G. Ghosn, N. Sudheendran, M. Wendt, A. Glasser, V. V. Tuchin, and K. V. Larin, "Monitoring of glucose permeability in monkey skin in vivo using Optical Coherence Tomography," Journal of Biophotonics 3(1-2), 25-33 (2010).

53. A. N. Bashkatov, E. A. Genina, Yu. P. Sinichkin, V. I. Kochubey, N. A. Lakodina, and V. V. Tuchin, "Glucose and mannitol diffusion in human dura mater," Biophysical Journal 85(5), 3310-3318 (2003).

54. M. Kreft, M. Luksic, T. M. Zorec, M. Prebil, and R. Zorec, "Diffusion of D-glucose measured in the cytosol of a single astrocyte," Cellular and Molecular Life Sciences 70(8), 1483-1492 (2012).

55. M. G. Ghosn, E. F. Carbajal, N. A. Befrui, and K. V. Larin, "Permeability of Hyperosmotic Agent in Normal and Atherosclerotic Vascular Tissues," Journal Of Biomedical Optics 13(1), 010505 (2008).

56. X. Guo, G. Wu, H. Wei, X. Deng, H. Yang, Y. Ji, Y. He, Z. Guo, S. Xie, H. Zhong, Q. Zhao, and Z. Zhu, "Quantification of Glucose Diffusion in Human Lung Tissues by Using Fourier Domain Optical Coherence Tomography," Photochemistry and Photobiology 88(2), 311-316 (2012).

57. F. Quondamatteo, "Skin and diabetes mellitus: what do we know?" Cell and Tissue Research 355(1), 1-21 (2014). 
58. G. M. Campos de Macedo, S. Nunes, and T. Barreto, "Skin disorders in diabetes mellitus: an epidemiology and physiopathology," Diabetology \& Metabolic Syndrome 8(1), 63 (2016)

59. J. A. Suaya, D. F. Eisenberg, C. Fang, and L. G. Miller, "Skin and Soft Tissue Infections and Associated Complications among Commercially Insured Patients Aged 0-64 Years with and without Diabetes in the U.S.," PLOS One 8(4), e60057 (2013).

60. M. Marre, "Genetics and the prediction of complications in type 1 diabetes," Diabetes Care 22(2), B53-B58 (1999).

61. I. J. Goldberg, "Why does diabetes increase atherosclerosis? I don't know!” Journal of Clinical Investigation 114(5), 613-615 (2004).

62. W. W. Song, A. Ergul, "Type-2 diabetes-induced changes in vascular extracellular matrix gene expression: Relation to vessel size," Cardiovascular Diabetology 5, 3 (2006).

63. G. Spinetti, N. Kraenkel, C. Emanueli, and P. Madeddu, "Diabetes and vessel wall remodelling: from mechanistic insights to regenerative therapies," Cardiovascular Research 78(2), 265-273 (2008).

64. D. Pedicino, A. F. Giglio, V. A. Galiffa, F. Trotta and G. Liuzzo, "Type 2 Diabetes, Immunity and Cardiovascular Risk: A Complex Relationship," Chap. 3 in Pathophysiology and Complications of Diabetes Mellitus, O. O. Oguntibeju (Ed.), InTech (2012).

65. M. S. Anderson, J. A. Bluestone, "The NOD mouse: a model of immune dysregulation," Annual Review of Immunology 23(1), 447-485 (2005).

66. J. A. Bluestone, K. Herold, and G. Eisenbarth, "Genetics, pathogenesis and clinical interventions in type 1 diabetes," Nature 464(7293), 1293-1300 (2010).

67. S. Makino, K. Kunimoto, Y. Muraoka, Y. Mizushima, K. Katagiri, and Y. Tochino, "Breeding of a non-obese, diabetic strain of mice," Experimental Animals 29(1), 1-13 (1980).

68. T. T. Berezov, B. F. Korovkin, Biological Chemistry, Meditsina, Moscow (1998) [in Russian].

69. B. Coudrillier, J. Pijanka, J. Jefferys, T. Sorensen, H. A. Quigley, C. Boote, and T. D. Nguyen, “Collagen Structure and Mechanical Properties of the Human Sclera: Analysis for the Effects of Age," Journal of Biomechanical Engineering 137(4), 041006 (2015).

70. M. Maciążek-Jurczyk, A. Szkudlarek, M. Chudzik, J. Pożycka, and A. Sułkowska, “Alteration of human serum albumin binding properties induced by modifications: A review," Spectrochimica Acta Part A: Molecular and Biomolecular Spectroscopy 188, 675-683 (2018).

71. S. F. Diniz, F. P. L. G. Amorim, F. F. Cavalcante-Neto, A. L. Bocca, A. C. Batista, G. E. P. M. Simm, and T. A. Silva, "Alloxan-induced diabetes delays repair in a rat model of closed tibial fracture," Brazilian Journal Of Medical and Biological Research 41(5), 373-379 (2008).

72. D. Dufrane, M. van Steenberghe, Y. Guiot, R. M. Goebbels, A. Saliez, and P. Gianello, "Streptozotocininduced diabetes in large animals (pigs/primates): role of GLUT2 transporter and beta-cell plasticity," Transplantation 81(1), 36-45 (2006).

73. L. M. Hansen, D. Gupta, G. Joseph, D. Weiss, and W. R. Taylor, "The receptor for advanced glycation end products impairs collateral formation in both diabetic and non-diabetic mice," Laboratory Investigation 97(1), 34-42 (2017).

74. H. Yu, J. Zhen, B. Pang, J. Gu, and S. Wu, "Ginsenoside Rg1 ameliorates oxidative stress and myocardial apoptosis in streptozotocin-induced diabetic rats," Journal of Zhejiang University-SCIENCE B, 16(5), 344354 (2015).

75. J. Wu, L. Yan, "Streptozotocin-induced type 1 diabetes in rodents as a model for studying mitochondrial mechanisms of diabetic $\beta$ cell glucotoxicity," Diabetes, Metabolic Syndrome and Obesity: Targets and Therapy 8, 181-188 (2015).

76. M. I. Asrarov, M. K. Pozilov, N. A. Ergashev, and M. M. Rakhmatullaeva, "The influence of the hypoglycemic agent glycorazmulin on the functional state of mitochondria in the rats with streptozotocininduced diabetes," Problems of Endocrinology 60(3), 38-42 (2014) [in Russian].

77. L. Dancakova, T. Vasilenko, I. Kova, K. Jakubcova, M. Holly, V. Revajova, F. Sabol, Z. Tomori, M. Iversen, P. Gal, and J. M. Bjordal, "Low-Level Laser Therapy with $810 \mathrm{~nm}$ Wavelength Improves Skin Wound Healing in Rats with Streptozotocin-Induced Diabetes," Photomedicine and Laser Surgery 32(4), 198-204 (2014).

78. D. E. Kelley, J. He, E. V. Menshikova, and V. B. Ritov, "Dysfunction of Mitochondria in Human Skeletal Muscle in Type 2 Diabetes," Diabetes 51(10), 2944-2950 (2002).

79. C. Moran, G. Münch, J. M. Forbes, R. Beare, L. Blizzard, A. J. Venn, T. G. Phan, J. Chen, and V. Srikanth, "Type 2 Diabetes, Skin Autofluorescence, and Brain Atrophy," Diabetes 64(1), 279-283 (2015).

80. D. Ziegler, N. Papanas, A. Zhivov, S. Allgeier, K. Winter, I. Ziegler, J. Brüggemann, A. Strom, S. Peschel, B. Köhler, O. Stachs, R. F. Guthoff, and M. Roden, "Early Detection of Nerve Fiber Loss by Corneal Confocal Microscopy and Skin Biopsy in Recently Diagnosed Type 2 Diabetes,” Diabetes 63(7), 2454-2463 (2014).

81. M. F. Chowdhry, H. A. Vohra, and M. Galiñanes, "Diabetes increases apoptosis and necrosis in both ischemic and nonischemic human myocardium: Role of caspases and poly-adenosine diphosphate-ribose polymerase," The Journal of Thoracic and Cardiovascular Surgery 134(1), 124-131 (2007). 
82. V. M. Monnier, D. R. Sell, C. Strauch, W. Sun, J. M. Lachin, P. A. Cleary, S. Genuth, and the DCCT Research Group, "The association between skin collagen glucosepane and past progression of microvascular and neuropathic complications in type 1 diabetes," Diabetes Complications 27(2), 141-149 (2013).

83. J. R. Acosta, I. Douag, D. P. Andersson, J. Bäckdahl, M. Rydén, P. Arner, and J. Laurencikiene, "Increased fat cell size: a major phenotype of subcutaneous white adipose tissue in non-obese individuals with type 2 diabetes," Diabetologia 59(3), 560-570 (2016).

84. E. V. Zharkikh, V. V. Dremin, M. A. Filina, I. N. Makovik, E. V. Potapova, E. A. Zherebtsov, A. I. Zherebtsova, and A. V. Dunaev, "Application of optical non-invasive methods to diagnose the state of the lower limb tissues in patients with diabetes mellitus," Journal of Physics: Conference Series 929, 012069 (2017).

85. V. Dremin, E. Zherebtsov, V. Sidorov, A. Krupatkin, I. Makovik, A. Zherebtsova, E. Zharkikh, E. Potapova, A. Dunaev, A. Doronin, A. Bykov, I. Rafailov, K. Litvinova, S. Sokolovski, and E. Rafailov, "Multimodal optical measurement for study of lower limb tissue viability in patients with diabetes mellitus," Journal of Biomedical Optics 22(8), 085003 (2017).

86. E. V. Potapova, V. V. Dremin, E. A. Zherebtsov, I. N. Makovik, E. V. Zharkikh, A. V. Dunaev, O. V. Pilipenko, V. V. Sidorov, and A. I. Krupatkin, "A complex approach to noninvasive estimation of microcirculatory tissue impairments in feet of patients with diabetes mellitus using spectroscopy," Optics and spectroscopy 123(6), 955-964 (2017).

87. L. A. Muir, C. K. Neeley, K. A. Meyer, N. A. Baker, A. M. Brosius, A. R. Washabaugh, O. A. Varban, J. F. Finks, B. F. Zamarron, C. G. Flesher, J. S. Chang, J. B. DelProposto, L. Geletka, G. Martinez-Santibanez, N. Kaciroti, C. N. Lumeng, and R. W. O’Rourke, “Adipose Tissue Fibrosis, Hypertrophy, and Hyperplasia: Correlations with Diabetes in Human Obesity," Obesity 24(3), 597-605 (2016).

88. P. Martín-Mateos, F. Dornuf, B. Duarte, B. Hils, A. Moreno-Oyervides, O. Elias Bonilla-Manrique, F. Larcher, V. Krozer, and P. Acedo, "In-vivo, non-invasive detection of hyperglycemic states in animal models using mm-wave spectroscopy,” Scientific Reports 6(1), 34035 (2016).

89. A. Rohilla, S. Ali, “Alloxan Induced Diabetes: Mechanisms and Effects," International journal of research in pharmaceutical and biomedical sciences 3(2), 819-823 (2012).

90. R. Bansal, N. Ahmad, and J. R. Kidwai, "Alloxan-glucose interaction: effect on incorporation of 14C-leucine into pancreatic islets of rat," Acta Diabetologica Latina 17(2), 135-143 (1980).

91. J. H. Lee, S. H. Yang, J. M. Oh, and M. G. Lee, "Pharmacokinetics of drugs in rats with diabetes mellitus induced by alloxan or streptozocin: comparison with those in patients with type I diabetes mellitus," Journal of Pharmacy and Pharmacology 62(1), 1-23 (2010).

92. J. R. Garrett, J. Ekström, and L. C. Anderson (Eds.), Frontiers of Oral Biology: Glandular Mechanisms of Salivary Secretion, 10 (1998).

93. N. Rakieten, M. L. Rakieten, and M. V. Nadkarni, "Studies on the diabetogenic action of streptozotocin," Cancer Chemotherapy Reports 29, 91-98 (1963).

94. K. Srinivasan, P. Ramarao, "Animal models in type 2 diabetes research: an overview," Indian Journal of Medical Research 125, 451-472 (2007).

95. Y. Dekel, Y. Glucksam, I. Elron-Gross, and R. Margalit, "Insights into modeling streptozotocin-induced diabetes in ICR mice," Lab Animal 38(2), 55-60 (2009).

96. K. Hayashi, R. Kojima, and M. Ito, "Strain differences in the diabetogenic activity of streptozotocin in mice," Biological \& Pharmaceutical Bulletin 29(6), 1110-1119 (2006).

97. M. Elsner, M. Tiedge, and S. Lenzen, "Mechanism underlying resistance of human pancreatic beta cells against toxicity of streptozotocin and alloxan," Diabetologia 46(12), 1713-1714 (2003).

98. Y. Yang, P. Santamaria, "Lessons on autoimmune diabetes from animal models," Clinical Science 110(6), 627-639 (2006).

99. T. Hanafusa, J. Miyagawa, H. Nakajima, K. Tomita, M. Kuwajima, Y. Matsuzawa, and S. Tarui, “The NOD mouse," Diabetes Research and Clinical Practice 24, S307-S311 (1994).

100.J. P. Mordes, R. Bortell, E. P. Blankenhorn, A. A. Rossini, and D. L. Greiner, "Rat models of type 1 diabetes: genetics, environment, and autoimmunity,” ILAR Journal 45(3), 278-291 (2004).

101.X. Wang, D. C. DuBois, S. Sukumaran, V. Ayyar, W. J. Jusko, and R. R Almon, "Variability in Zucker diabetic fatty rats: differences in disease progression in hyperglycemic and normoglycemic animals," Diabetes, Metabolic Syndrome and Obesity: Targets and Therapy 7, 531-541 (2014).

102.S. Yoshida, H. Tanaka, H. Oshima, T. Yamazaki, Y. Yonetoku, T. Ohishi, T. Matsui, and M. Shibasaki, "AS1907417, a novel GPR119 agonist, as an insulinotropic and beta-cell preservative agent for the treatment of type 2 diabetes," Biochemical and Biophysical Research Communications 400(4), 745-751 (2010).

103. V. A. Gault, B. D. Kerr, P. Harriott, and P. R. Flatt, “Administration of an acylated GLP-1 and GIP preparation provides added beneficial glucose-lowering and insulinotropic actions over single incretins in mice with Type 2 diabetes and obesity," Clinical Science 121(3), 107-117 (2011). 
104.J. S. Park, S. D. Rhee, N. S. Kang, W. H. Jung, H. Y. Kim, J. H. Kim, S. K. Kang, H. G. Cheon, J. H. Ahn, and K. Y. Kim, "Anti-diabetic and anti-adipogenic effects of a novel selective 11beta-hydroxysteroid dehydrogenase type 1 inhibitor, 2-(3-benzoyl)-4-hydroxy-1,1-dioxo-2H-1,2-benzothiazine-2-yl-1phenylethanone (KR-66344)," Biochemical Pharmacology 81(8), 1028-1035 (2011).

105.P. Lindstrom, "The physiology of obese-hyperglycemic mice [ob/ob mice]," Scientific world journal 7, 666685 (2007).

106.T. Bock, B. Pakkenberg, and K. Buschard, "Increased islet volume but unchanged islet number in ob/ob mice," Diabetes 52(7), 1716-1722 (2003).

107.F. F. Chehab, M. E. Lim, and R. Lu, "Correction of the sterility defect in homozygous obese female mice by treatment with the human recombinant leptin," Nature Genetics 12(3), 318-320 (1996).

108.H. Chen, O. Charlat, L. A. Tartaglia, E. A. Woolf, X. Weng, S. J. Ellis, N. D. Lakey, J. Culpepper, K. J. More, R. E. Breitbart, G. M. Duyk, R. I. Tepper, and J. P. Morgenstern, "Evidence that the diabetes gene encodes the leptin receptor: identification of a mutation in the leptin receptor gene in db/db mice," Cell 84(3), 491-495 (1996).

109.A. Pick, J. Clark, C. Kubstrup, M. Levisetti, W. Pugh, S. Bonner-Weir, and K. S. Polonsky, "Role of apoptosis in failure of beta-cell mass compensation for insulin resistance and beta-cell defects in the male Zucker diabetic fatty rat," Diabetes 47(3), 358-364 (1998).

110.T. Shibata, S. Takeuchi, S. Yokota, K. Kakimoto, F. Yonemori, and K. Wakitani, "Effects of peroxisome proliferator-activated receptor-alpha and -gamma agonist, JTT-501, on diabetic complications in Zucker diabetic fatty rats," British Journal of Pharmacology 130(3), 495-504 (2000).

111.V. M. Monnier, D. R. Sell, "Prevention and repair of protein damage by the Maillard reaction in vivo," Rejuvenation Research 9(2), 264-273 (2006).

112.Q. A. Kleter, J. J. M. Damen, M. J. Buijs, and J. M. Ten Cate, “The Maillard reaction in demineralized dentin in vitro," European Journal of Oral Sciences 105(3), 278-284 (1997).

113.A. Ioannou, C. Varotsis, "Modifications of hemoglobin and myoglobin by Maillard reaction products (MRPs)," PLoS ONE 12(11), e0188095 (2017).

114.R. D. G. Leslie, D. C. Robbins (Eds.), Diabetes: Clinical Science in Practice, Cambridge University Press (1995).

115.A. M. Schmidt, O. Hori, J. X. Chen, J. F. Li, J. Crandall, J. Zhang, R. Cao, S. D. Yan, J. Brett, and D. Stem, "Advanced Glycation Endproducts Interacting with Their Endothelial Receptor Induce Expression of Vascular Cell Adhesion Molecule-1 (VCAM-1) in Cultured Human Endothelial Cells and in Mice. A Potential Mechanism for the Accelerated Vasculopathy of Diabetes," Journal of Clinical Investigation 96, 1395-1403 (1995).

116.J. Kinnunen, H. T. Kokkonen, V. Kovanen, M. Hauta-Kasari, P. Vahimaa, M. J. Lammi, J. Töyräs, and J. S. Jurvelinb, "Nondestructive fluorescence-based quantification of threose-induced collagen cross-linking in bovine articular cartilage," Journal of Biomedical Optics 17(9), 0970031 (2012).

117.G. T. Wondrak, M. J. Roberts, D. Cervantes-Laurean, M. K. Jacobson, and E. L. Jacobson, "Proteins of the extracellular matrix are sensitizers of photo-oxidative stress in human skin cells," Journal of Investigative Dermatology 121(3), 578-586 (2003).

118.M. Yokota, Y. Tokudome, "The Effect of Glycation on Epidermal Lipid Content, Its Metabolism and Change in Barrier Function," Skin Pharmacology and Physiology 29(5), 231-242 (2016).

119.E. L. Hull, M. N. Ediger, A. N. T. Unione, E. K. Deemer, M. L. Stroman, and J. W. Baynes, "Noninvasive, optical detection of diabetes: model studies with porcine skin," Optics Express 12(19), 4496-4510 (2004).

120.V. M. Monnier, W. Sun, X. Gao, D. R Sell, P. A. Cleary, J. M. Lachin, S. Genuth, and The DCCT/EDIC Research Group, "Skin collagen advanced glycation endproducts (AGEs) and the long- term progression of sub- clinical cardiovascular disease in type 1 diabetes," Cardiovascular Diabetology 14, 118 (2015).

121.S. Genuth, W. Sun, P. Cleary, X. Gao, D. R. Sell, J. Lachin, and V. M. Monnier, "Skin Advanced Glycation End Products Glucosepane and Methylglyoxal Hydroimidazolone Are Independently Associated With Longterm Microvascular Complication Progression of Type 1 Diabetes," Diabetes 64(1), 266-278 (2015).

122.O. S. Zhernovaya, V. V. Tuchin, and I. V. Meglinski, "Monitoring of blood proteins glycation," Laser Physics Letters 5(6), 460-464 (2008).

123.B.-M. Kim, J. Eichler, K. M. Reiser, A. M. Rubenchik, and L. B. Da Silvam, "Collagen structure and nonlinear susceptibility: effects of heat, glycation, and enzymatic cleavage on second harmonic signal intensity," Lasers in Surgery and Medicine 27(4), 329-335 (2000).

124.B. Gopalkrishnapillai, V. Nadanathangam, N. Karmakar, S. Anand, and A. Misra, "Evaluation of autofluorescent property of hemoglobin-advanced glycation end product as a long-term glycemic index of diabetes," Diabetes 52(4), 1041-1046 (2003).

125.Y.-J. Hwang, J. Granelli, and J. Lyubovitsky, "Multiphoton optical image guided spectroscopy method for characterization of collagen-based materials modified by glycation," Analytical Chemistry 83(1), 200-206 (2011). 
126.P. A. Cleary, B. H. Braffett, T. Orchard, T. J. Lyons, J. Maynard, C. Cowie, R. A. Gubitosi-Klug, J. Way, K. Anderson, A. Barnie, and S. Villavicencio, "Clinical and Technical Factors Associated with Skin Intrinsic Fluorescence in Subjects with Type 1 Diabetes from the Diabetes Control and Complications Trial/Epidemiology of Diabetes Interventions and Complications Study," Diabetes Technology \& Therapeutics 15(6), 466-474 (2013).

127.E. Sugisawa, J. Miura, Y. Iwamoto, and Y. Uchigata, "Skin Autofluorescence Reflects Integration of Past Long-Term Glycemic Control in Patients With Type 1 Diabetes," Diabetes Care 36(8), 2339-2345 (2013).

128.J. D. Maynard, M. N. Ediger, R. D Johnson, and M. R. Robinson, Determination of a measure of a glycation end-product or disease state using a flexible probe to determine tissue fluorescence of various sites, Patent US11677498 USA, MPK A61B 6/00, Assignee: VeraLight, Inc., Albuquerque, NM (US), Appl. No.: $11 / 677,498(2012)$.

129.J. Lin, J. Lin, Z. Huang, P. Lu, J. Wang, X. Wang, and R. Chen, "Raman spectroscopy of human hemoglobin for diabetes detection,” Journal of Innovative Optical Health Sciences 7(1), 1350051 (2014).

130.K. Sangkyu, L. Joonhyung, Noninvasive apparatus and method for testing glycated hemoglobin, Patent 9841415, Assignee: Samsung Electronics Co., Ltd. (Suwon-si, KR), United States (2017).

131.M. Mallya, R. Shenoy, G. Kodyalamoole, M. Biswas, J. Karumathil, and S. Kamath, "Absorption Spectroscopy for the Estimation of Glycated Hemoglobin (HbA1c) for the Diagnosis and Management of Diabetes Mellitus: A Pilot Study," Photomedicine and Laser Surgery 31(5), 219-224 (2013).

132.T. Pan, M. Li, J. Chen, and H. Xue, "Quantification of glycated hemoglobin indicator HbA1c through nearinfrared spectroscopy,” Journal of Innovative Optical Health Sciences 7(4), 1350060 (2014).

133.M. Rendell, T. Bergman, G. O’Donnell, E. Drobny, J. Borgos, and R. Bonnor, "Microvascular blood flow, volume, and velocity, measured by laser Doppler techniques in IDDM," Diabetes 38(7), 819-824 (1989).

134.H. M. Raabe, H. Molsen, S.-M. Mlinaric, Y. Acil, G. H. G. Sinnecker, H. Notbohm, K. Kruse, and P. K. Muller, "Biochemical alterations in collagen IV induced by in vitro glycation," Biochemical Journal 319(3), 699-704 (1996).

135.O. S. Zhernovaya, A. N. Bashkatov, E. A. Genina, V. V. Tuchin, I. V. Meglinski, D. Yu. Churmakov, and L. J. Ritchie, "Investigation of glucose-hemoglobin interaction by optical coherence tomography," Proceedings of SPIE 6535, 65351C (2007).

136.E. I. Galanzha, A. V. Solovieva, V. V. Tuchin, R. K. Wang, and S. G. Proskurin, “Application of optical coherence tomography for diagnosis and measurements of glycated hemoglobin," Proceedings of SPIE 5140, 125-132 (2003).

137.V. V. Tuchin, R. K. Wang, E. I. Galanzha, J. B. Elder, and D. M. Zhestkov, "Monitoring of glycated hemoglobin by OCT measurement of refractive index," Proceedings of SPIE 5316, 66-77 (2004).

138.P. J. Higgins, H. F. Bunn, "Kinetic analysis of the nonenzymatic glycosylation of hemoglobin," The Journal of Biological Chemistry 256(10), 05204-5208 (1981).

139.G. K. Reddy, "Cross-Linking in Collagen by Nonenzymatic Glycation Increases the Matrix Stiffness in Rabbit Achilles Tendon," Experimental Diabesity Research 5(2), 143-153 (2004).

140.B. E. Sherlock, J. N. Harvestine, D. Mitra, A. Haudenschild, J. Hu, K. A. Athanasiou, J. K. Leach, and L. Marcua, "Nondestructive assessment of collagen hydrogel cross-linking using time-resolved autofluorescence imaging," Journal of Biomedical Optics 23(3), 036004 (2018)

141.M. Mernea, A. Ionescu, I. Vasile, C. Nica, G. Stoian, T. Dascalu, and D. F. Mihailescu, "In vitro human serum albumin glycation monitored by Terahertz spectroscopy," Optical and Quantum Electronics 47(4), 961-973 (2015).

142.A. Goldin, J. A. Beckman, A. M. Schmidt, and M. A. Creager, "Advanced Glycation End Products Sparking the Development of Diabetic Vascular Injury," Circulation 114(6), 597-605 (2006).

143. V. L. Emanuel, I. Yu. Karyagina, and Yu. V. Emanuel, "Comparison of method for determining glycosylated hemoglobin," Laboratornaya meditsina 5, 98-104 (2002) [in Russian].

144.V. V. Tuchin, Lasers and Fibre Optics in Biomedical Science, Fizmatlit, Moscow (2010) [in Russian].

145.V. V. Tuchin, Optics of Biological Tissues. Methods of Light Scattering in Medical Diagnostics, Fizmatlit, Moscow (2012) [in Russian].

146.J. Wang, N. Ma, R. Shi, Y. Zhang, T. Yu, and D. Zhu, "Sugar-induced skin optical clearing: from molecular dynamics simulation to experimental demonstration," IEEE Journal of Selected Topics in Quantum Electronics 20(2), 256-262 (2014).

147.E. A. Genina, A. N. Bashkatov, and V. V. Tuchin, “Tissue optical immersion clearing," Expert Review of Medical Devices 7(6), 825-842 (2010).

148.F. S. Pavone, P. J. Campagnola (Eds.), "SHG and Optical Clearing," Chap. 8 in Second Harmonic Generation Imaging, CRC Press, Taylor \& Francis Group, Boca Raton, London, NY, 169-189 (2014).

149.E. A. Genina, A. N. Bashkatov, K. V. Larin, and V. V. Tuchin, "Light-Tissue Interaction at Optical Clearing," Chap. 7 in Laser Imaging and Manipulation in Cell Biology, F.S. Pavone (Ed.), Wiley-VCH Verlag GmbH \& Co. KGaA, Weinheim, 113-164 (2010). 
150.L. Shi, L.A. Sordillo, A. Rodriguez-Contreras, and R. Alfano, "Transmission in near-infrared optical windows for deep brain imaging," Journal of Biophotonics 9(1-2), 38-43 (2015).

151.D. C. Sordillo, L. A. Sordillo, P. P. Sordillo, and R. R. Alfano, "Fourth Near-Infrared Optical Window for Assessment of Bone and other Tissues," Proceedings of SPIE 9689, 96894J (2016).

152.L. A. Sordillo, Y. Pu, S. Pratavieira, Y. Budansky, and R. R. Alfano, "Deep optical imaging of tissue using the second and third near-infrared spectral windows," Journal of Biomedical Optics, 19(5), 056004 (2014).

153.S. Y. Lee, H. J. Park, K. Kim, Y. H. Sohn, S. Jang, and Y. K. Park, "Refractive index tomograms and dynamic membrane fluctuations of red blood cells from patients with diabetes mellitus," Scientific Reports 7(1), 1039 (2017).

154.R. M. A. Henry, P. J. Kostense, A. M. W. Spijkerman, J. M. Dekker, G. Nijpels, R. J. Heine, O. Kamp, N. Westerhof, L. M. Bouter, and C. D. A. Stehouwer, "Arterial Stiffness Increases With Deteriorating Glucose Tolerance Status," Circulation 107(16), 2089-2095 (2003).

155.E. Danese, M. Montagnana, A. Nouvenne, and G. Lippi, “Advantages and Pitfalls of Fructosamine and Glycated Albumin in the Diagnosis and Treatment of Diabetes," Journal of Diabetes Science and Technology 9(2), 169-176 (2015).

156.A. Yuen, C. Laschinger, I. Talior, W. Lee, M. Chan, J. Birek, E. W. K. Young, K. Sivagurunathan, E. Won, C. A. Simmons, and C. A. McCulloch, "Methylglyoxal-modified collagen promotes myofibroblast differentiation," Matrix Biology 29(6), 537-548 (2010).

157.A. Ghazaryan, M. Omar, G. J. Tserevelakis, and V. Ntziachristos, "Optoacoustic detection of tissue glycation," Biomedical Optics Express 6(9), 3149 (2015).

158.M. Gniadecka, O. F. Nielsen, S. Wessel, M. Heidenheim, D. H. Christensen, and H. C. Wulf, "Water and protein structure in photoaged and chronically aged skin,” Journal of Investigative Dermatology 111(6), 11291133 (1998).

159.D. K. Tuchina, A. N. Bashkatov, E. A. Genina, and V. V. Tuchin, Biosensor for noninvasive optical monitoring of the pathology of biological tissues, Patent RF No. 2633494, MPK A61B 5/05, G01N 21/01, Patent holder: N.G. Chernyshevsky Saratov State University, Application No. 2016102046, 22.01.2016, Bul. No. 29 (2017).

160.L. M. Oliveira, M. I. Carvalho, E. M. Nogueira, and V. V. Tuchin, "Diffusion characteristics of ethylene glycol in skeletal muscle," Journal of Biomedical Optics 20(5), 051019 (2015).

161.J.-M. Andanson, K. L. A. Chan, and S. G. Kazarian, "High-throughput spectroscopic imaging applied to permeation through the skin," Applied Spectroscopy 63(5), 512-517 (2009).

162.M. J. Choi, H. I. Maibach, "Elastic vesicles as topical/transdermal drug delivery systems," International Journal of Cosmetic Science 27(4), 211-221 (2005).

163.N. Akhtar, "Vesicles: a recently developed novel carrier for enhanced topical drug delivery," Current Drug Delivery 11(1), 87-97 (2014).

164.L. C. Freitas Lima, V. Andrade Braga, M. S. França Silva, J. Campos Cruz, S. H. Sousa Santos, M. M. Oliveira Monteiro, and C. Moura Balarini, "Adipokines, diabetes and atherosclerosis: an inflammatory association," Frontiers in Physiology 6, 304 (2015).

165.D. Schweitzer, L. Deutsch, M. Klemm, S. Jentsch, M. Hammer, S. Peters, J. Haueisen, U. A. Müller, and J. Dawczynskid, "Fluorescence lifetime imaging ophthalmoscopy in type 2 diabetic patients who have no signs of diabetic retinopathy," Journal of Biomedical Optics 20(6), 061106 (2015).

166.C. Ghosh, P. Mukhopadhyay, S. Ghosh, and M. Pradhan, "Insulin sensitivity index (ISI $\left.{ }_{0,120}\right)$ potentially linked to carbon isotopes of breath $\mathrm{CO}_{2}$ for prediabetes and type 2 diabetes," Scientific Reports 5(1), 11959 (2015).

167.C.-M. Cheng, Y.-F. Chang, H.-C. Chiang, and C.-W. Chang, "Optical coherence tomography for the structural changes detection in aging skin," Proceedings of SPIE 10456, 104565B (2018).

168.D. G. Dyer, J. A. Dunn, S. R. Thorpe, K. E. Bailie, T. J. Lyons, D. R. McCance, and J. W. Baynes, "Accumulation of Maillard Reaction Products in Skin Collagen in Diabetes and Aging," Journal of Clinical Investigation 91(6), 2463 (1993).

169.S. Sakai, K. Kikuchi, J. Satoh, H. Tagami, and S. Inoue, "Functional properties of stratum corneum in patients with diabetes mellitus: similarities to senile xerosis," British Journal of Dermatology 153(2), 319-323 (2005).

170.H. Y. Park, H. J. Kim, M. Jung, C. H. Chung, R. Hasham, C. S. Park, and E. H. Choi, "A long-standing hyperglycaemic condition impairs skin barrier by accelerating skin ageing process," Experimental Dermatology 20(12), 969-974 (2011).

171.S. Sakai, Y. Endo, N. Ozawa, T. Sugawara, A. Kusaka, T. Sayo, H. Tagami, and S. Inoue, "Characteristics of the epidermis and stratum corneum of hairless mice with experimentally induced diabetes mellitus," Journal of Investigative Dermatology 120(1), 79-85 (2003).

172.K. R. Taylor, A. E. Costanzo, and J. M. Jameson, "Dysfunctional $\gamma \delta \mathrm{T}$ cells contribute to impaired keratinocyte homeostasis in mouse models of obesity," Journal of Investigative Dermatology 131(12), 24092418 (2011). 
173.P. Zakharov, M. S. Talary, I. Kolm, and A. Caduff, "Full-field optical coherence tomography for the rapid estimation of epidermal thickness: study of patients with diabetes mellitus type 1," Physiological Measurement 31(2), 193-205 (2010).

174.X. Chen, W. Lin, S. Lu, T. Xie, G. Kui, Y. Shi, J. Zou, Z. Liu, and W. Liao, "Mechanisitic study of endogenous skin lesions in diabetic rats," Experimental Dermatology 19(12), 1088-1095 (2010).

175.U. Bertheim, A. Engstorm-Laurent, P. Hofer, P. Hallgren, J. Asplund, and S. Hellstrom, "Loss of hyaluronan in the basement membrane zone of the skin correlates to the degree of stiff hands in diabetic patients," Acta Dermato-Venereologica 82(5), 329-334 (2002).

176.J. G. B. Derraik, M. Rademaker, W. S. Cutfield, T. E. Pinto, S. Tregurtha, A. Faherty, J. M. Peart, P. L. Drury, and P. L. Hofman, "Effects of Age, Gender, BMI, and Anatomical Site on Skin Thickness in Children and Adults with Diabetes," PLoS ONE 9(1), e86637 (2014).

177.A. A. Tahrani, W. Zeng, J. Sakher, M. K. Piya, S. Hughes, K. Dubb, and M. J. Stevens, “Cutaneous structural and biochemical correlates of foot complications in high-risk diabetes," Diabetes Care 35(9), 1913-1918 (2012).

178.N. C. Avery, A. J. Bailey, "The effects of the Maillard reaction on the physical properties and cell interactions of collagen," Pathologie Biologie 54(7), 387-395 (2006).

179.A. J. Argyropoulos, P. Robichaud, R. M. Balimunkwe, G. J. Fisher, C. Hammerberg, Y. Yan, and T. Quan, "Alterations of Dermal Connective Tissue Collagen in Diabetes: Molecular Basis of Aged-Appearing Skin," PLoS ONE 11(4), e0153806 (2016).

180.L. V. Wang (Ed.), Photoacoustic Imaging and Spectroscopy, CRC Press (2009).

\section{Contents}

1 Introduction

2 Classification of diabetes mellitus

3 Experimental models of diabetes mellitus

4 Glycation and non-enzymatic glycation of proteins

5 Optical and structural properties of biological tissues

5.1 Blood and cardiovascular system

5.2 Different tissues

5.3 Skin

6 Conclusion

\section{Introduction}

Diabetes mellitus is a chronic endocrine diseasecaused by the increased content of free glucose in organism, which results in the violation of metabolism in the organism. According to the prognosis of the World Health Organisation, the diabetes mellitus will move from the eighth to the seventh position in the list of the most widespread causes of death, the mortality growth in 2030 compared to 2010 amounting to $54 \%$ [1]. The numbers of patients suffering from diabetes mellitus has grown by approximately four times from 1980 (108 million people) to 2014 (422 million people) [2, 3].

The normal content of free glucose (glycaemia) in blood amounts to $3.3-5.5 \mathrm{mmol} / \mathrm{l}(60-100 \mathrm{mg} / \mathrm{dl})$ [4]. The glucose is a monosaccharide that plays an important role in the functioning of a living organism. It is a source of energy providing metabolic processes in the organism. To regulate the glucose metabolism, the pancreas beta cells produce the peptide hormone insulin. The insufficient insulin production by the pancreas, or the abnormal reaction of the organism cells to the produced insulin, leads to the excess glucose content in the blood. Long-term increase of the glucose content in blood (above $11 \mathrm{mmol} / \mathrm{l}(200 \mathrm{mg} / \mathrm{dl})$ ) (hyperglycemia) leads to excess glucose content in the interstitial fluid, which violates the metabolism in the organism, causing the development of diabetes mellitus [2, 5-12].

It was supposed that the hyperglycemia could lead to increased oxidation of glucose and formation of superoxide radicals in mitochondria [13-15]. Anions of superoxide radicals are benign and nonreactive chemical substances, however, under some conditions, mainly in the presence of reductive-oxidative transition metals, such as iron and copper, they turn into highly reactive free radicals $[13,16]$. The transformation occurs via metal-mediated Haber-Weiss or Fenton reactions (Eqs. (1) and (2), respectively) [13]:

$$
\begin{aligned}
& \mathrm{O}_{2}^{--}+\mathrm{H}_{2} \mathrm{O}_{2} \stackrel{\mathrm{Fe} / \mathrm{Cu}}{\longrightarrow} \mathrm{O}_{2}+\mathrm{HO}^{-}+\mathrm{HO}^{-} \\
& \mathrm{Fe}^{2+} / \mathrm{Cu}^{+}+\mathrm{H}_{2} \mathrm{O}_{2} \rightarrow \mathrm{Fe}^{3+} / \mathrm{Cu}^{2+}+\mathrm{HO}^{-}+\mathrm{HO}^{\circ}
\end{aligned}
$$

For example, the hyperglycemia-induced overproduction of superoxide activates the hyperglycemic damage in endothelium cells of aorta. The damaging effect of superoxide leads to the redirection of glucose metabolism from the glycolytic path to alternative metabolic paths, including the formation of the advanced glycation end products.

Since the glucose level in blood is related to its level in the interstitial fluid, the hyperglycemia facilitates the metabolic disbalance and disturbance of the organs functioning [12, 17-19]. In this connection, many papers are aimed at determining the concentration of free glucose in blood, interstitial fluid, and other fluids of the body [20-30], revealing the morphological changes in vital organs [10, 12, 17, 31], designing biosensors for permanent monitoring of free glucose in the organism $[20,32]$, studying the effect of glucose on blood and proteins of tissues, developing the methods for diabetes monitoring based on the difference of optical properties between healthy and diabetic tissues [17, 20, 33-48], 
assessing the glucose diffusion rate in healthy [20, 4854] and pathological tissues (the walls of atherosclerotic blood vessels $[48,55]$ and malignant tumours [56]).

One third of all patients with diabetes mellitus have complications in the form of skin lesions, the most severe of them being the chronic ulcers that recover very slowly, thus increasing the risk of infection [19, 57-59]. Diabetes mellitus increases the risk of cardiovascular diseases, retinopathy that leads to blindness, neuropathy and nephropathy $[8-13,19,31$, 60-64]. According to the data of the World Health Organisation, diabetes mellitus is the main cause of heart attacks, myocardial infarction, brain stroke, blindness, renal failure, and amputation of lower extremities, i.e., a risk factor of many other diseases enhanced by the diabetes $[9,13,19,60,63,64]$.

Thus, diabetes mellitus is a cause of serious complications that should be prevented by inventing new methods of diabetes diagnostics and treatment and improving the existing ones, which requires careful examination of the disease development mechanisms, as well as developing simple and reliable methods and criteria for detecting the complication precursors.

The clinical course and complications of diabetes mellitus are widely studied using different physical methods, including the optical ones, which often allow a noninvasive monitoring of the key parameters of biological tissues in real time. The latter explains why the optical methods are considered as promising in medicine and the field of their application permanently expands. This paper presents a review of recent publications on the study of the changes of structural and optical properties under the development of diabetes mellitus using in vitro models of glycated tissues, in vivo experimental models of diabetes in laboratory animals, and clinical studies. Such analysis seems to be useful for further research and engineering activity in the field of noninvasive optical diagnostics of pathological conditions in human organism.

\section{Classification of diabetes mellitus}

Diabetes mellitus can be divided into two principal types: type I is the insulin-dependent diabetes ("diabetes of young", "immune-mediated diabetes"), type II is the insulin-independent diabetes ("diabetes of aged") $[8,9$, 19, 57]. They separately consider the gestational diabetes mellitus, diagnosed during pregnancy and not observed before it. One can also select specific types of the disease due to other causes. The examples include the monogenic diabetes syndrome, which is a result of mutant genes inheritance (diabetes of neonates), the diabetes caused by the diseases of exocrine pancreas (such as cystous fibrosis), the diabetes induced by a chemical agent (e.g., when medicines are used in HIV/AIDS treatment or after organ transplantation) [8].

Types I и II of diabetes mellitus are most widespread. Type I insulin-dependent diabetes mellitus is a consequence of the destruction of the pancreas beta cells that disturbs the insulin production. The amount of the produced insulin appears insufficient to process the amount of glucose received by the organism. The content of glucose in the organism increases, the chronical hyperglycemia arises, and the metabolism in a number of organs is disturbed [2, 5-9, 19, 64-67]. Type I diabetes mellitus is more frequent in young people, so that it is also referred to as "the diabetes of young". Type I diabetes mellitus comprises nearly $5-10 \%$ of the total number of patients, suffering from all types of diabetes mellitus [2, 8]. For type I diabetes mellitus such symptoms are characteristic as polyuria (excess urinary excretion), polydipsia (thirst), permanent hunger, loss of weight, visual impairment, and tiredness $[2,8,17,19,67]$.

Type II insulin-independent diabetes mellitus develops because of cell resistance to the produced insulin, the insulin deficiency being also present in the organism of the patient. Type II diabetes mellitus is wider spread and comprises about $90-95 \%$ of the total amount of diabetic patients. In this case, the disease develops in the middle age, so that this type of disease is often referred to as "the diabetes of aged." However, in recent time this type of diabetes mellitus more and more often appears in children. Diabetes mellitus is largely a result of excessive body mass and physical inactivity [2, $8,9,19,64]$. The symptoms of type I and II diabetes mellitus are alike, but in the second case they are often less expressed, because of which the disease is diagnosed in a few years after its beginning, when the complications already arise [2]. In the case of type II diabetes mellitus, the obesity of the patient is an additional symptom [9]. It is important to determine the type of diabetes mellitus for prescribing the most efficient therapy [8].

Under the excess injection of insulin or its excess production induced by medical preparations in patients with diabetes mellitus, the hypoglycaemic coma (crisis) can happen, when the glucose content in blood falls below $3.9 \mathrm{mmol} / 1(70 \mathrm{mg} / \mathrm{dl})$. In this case, the organism has not enough energy to support normal vital activity, which leads to weakness, trembling, irritability, tachycardia, and hunger, with possible loss of consciousness and fatal outcome [8]. The main cause of diabetes mellitus development is genetic predisposition $[8,19]$; the rest causes comprise mainly different diseases that disturb metabolism, as well as the insufficient physical activity [8].

The processes that accompany the aging of the organism become faster with the development of diabetes mellitus [63]. With age the water content in skin decreases, and, correspondingly, the ratio of the base substance and fibrous structures changes. The coefficient decreases at the expense of increasing the collagen content and decreasing the concentration of glycosaminoglycans. The content of hyaluronic acid considerably reduces. The physical and chemical properties of collagen change: the number and strength of inter- and intramolecular crosslinks increases, the elasticity and swelling ability reduces, the resistance against collagenase develops, the structural stability of collagen fibres, i.e., the maturation of fibrillar structures 
of the connective tissue progresses. The collagen aging is a result of metabolic processes that occur in the organism and affect the molecular structure of collagen. The connective tissue injury includes the damage of all structural parts of the tissue: the fibrils, the intercellular substance, and the cells [68]. In the studies of the human sclera aging using the wide-angle X-ray scattering, the structure of collagen fibers was investigated. It was found that with age the rigidity of the scleral matrix increases, the degree of fiber straightening and the mechanical anisotropy in the peripapillary sclera decreases [69]. The aging of organism is accompanied by structural and functional modifications of macromolecules [70]. The changes that occur in the tissues of the organism under the development of diabetes mellitus are investigated both in laboratory animals using experimental models [9-11, 17, 39, 40, $42,45-47,71-77]$ and directly in patients in the course of clinical examination [12, 35, 78-87].

\section{Experimental models of diabetes mellitus}

Among the models of diabetes mellitus, the chemically induced ones that allow relatively cheap and simple induction of pathology development in rodents are widely used. Similar models can be implemented also in higher animals [9-11, 17, 39, 40, 42, 45, 71-77, 88]. The most well-known and widely used methods of chemical diabetes induction are implemented using two compounds, streptozotocin [47, 73-77, 88] and alloxan $[17,39,40,42,45,46,71]$. Accumulated mainly in the pancreas, they provoke the production of radicals that cause the destruction of the pancreas beta cells and, therefore, disturb the insulin production $[9,10,11,75$, 89]. Since alloxan and streptozotocin have the structure resembling that of glucose, their accumulation occurs in the pancreas by means of glucose transporters, so that, as a rule, the animals are more susceptible to them on an empty stomach $[9,11,90]$. Thus, the injection of alloxan or streptozotocin to the animals induces the insulin-dependent (type I) diabetes mellitus [11, 89]. Since the solutions of alloxan and streptozotocin are relatively unstable, they should be prepared immediately before the injection. Note that these substances can possess different degrees of toxicity with respect to other organs, too $[9,90,91]$. Besides the destruction of beta cells, alloxan and streptozotocin are capable of modifying biological macromolecules and DNA fragmenting [9, 10, 11,89].

Dunn et al. gave the first description of the alloxan diabetes model in 1943 [11, 89, 92]. A single doze varies from 50 to $200 \mathrm{mg} / \mathrm{kg}$ of body mass for mice and from 40 to $200 \mathrm{mg} / \mathrm{kg}$ for rats, depending on the breed $[9,10,42]$. Alloxan is injected intravenously, intraperitoneally, or subcutaneously [10, 42, 76].

In 1963 Rakieten published a paper, reporting the capability of streptozotocin to induce diabetes mellitus $[11,75,93]$. The single maximal dose of streptozotocin is from 100 to $200 \mathrm{mg} / \mathrm{kg}$ for mice $[9,94,95]$ depending on the breed $[9,96]$ and from 35 to $65 \mathrm{mg} / \mathrm{kg}$ of body mass for rats $[9,94]$. There is also a method of injecting streptozotocin to animals by small dozes from 20 to $40 \mathrm{mg} / \mathrm{kg}$ during 5 days [9].

Note that in contrast to animals, in humans the beta cells of the pancreas are resistant against the toxicity of streptozotocin and alloxan [97]. It is also interesting that the glucose content variation in blood during the first week after the injection of alloxan and streptozotocin is nonlinear (Fig. 1). Immediately after the injection, the glucose content in blood increases during about 3-4 hours, which is accompanied by morphological changes of beta cells: intercellular vacuolisation, dilatation of rough endoplasmic reticulum, reduction of Golgi apparatus area, diminution of secretor granules and insulin content, swelling of mitochondria. Then the hypoglycaemic stage begins, during which in a few hours the glucose content in blood falls, and the hypoglycaemia can lead to fatal outcomes. Such dramatic transient hypoglycaemia appears in the process of insulin accumulation because of the secretory granule toxication and the cell membrane rupture. In addition to the morphological changes, the nuclei of beta cells become pyknotic [11]. In about 6 days after the injection the permanent diabetic hyperglycemic phase comes, for which the morphologically full degranulation and the loss of integrity of beta cells during 12-48 hours is observed $[9,11]$. In this connection, it is important to choose the appropriate terms of measuring the glucose content in blood in the process of diabetes modeling.

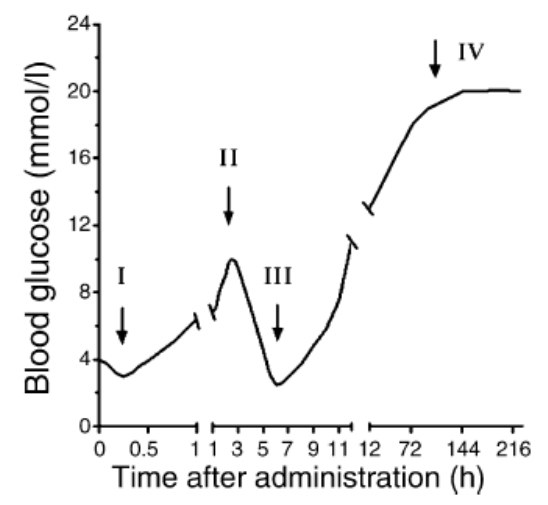

Fig. 1 Phases of free blood glucose variation after the injection of alloxan (I-IV) or streptozotocin (II-IV) [11].

The animals with the model diabetes are characterised by such symptoms as polyuria, polydipsia [67], and loss of body weight [9, 67], typical for type I diabetes mellitus.

Besides the above models of type I diabetes, there are also other ones, which are used less widely, e.g., the autoimmune modes of diabetes. The lines of mice with "spontaneous" diabetes mellitus ("non-obese diabetes") and biobreeding (BB) rats are created, in which from the very birth or in some time after the birth the prediabetic state of the organism develops [9, 66, 67, 98-100]. The Akita mouse lines, in which diabetes mellitus genetically develops in a few weeks after the birth are bred. The diabetes is also induced using viruses [9]. To model type II diabetes mellitus, mono- and polygenic models of obesity, the rats of the Zucker line, etc. are 
used $[9,101]$. The most widely used monogenic models of obesity possess defects in the transmission of leptin hormone signals. Leptin is responsible for the feeling of saturation, so that the absence of functional leptin in animals gives rise to hyperphagia (overeating) followed by obesity. The Lep ${ }^{\mathrm{ob} / \mathrm{ob}}$ and Lepr ${ }^{\mathrm{db} / \mathrm{db}}$ mice, the Zucker rats that possess no leptin receptor experience the lack of leptin. These models are often used to test new methods of type II diabetes treatment [9, 101-104].

In Lep ${ }^{\text {ob/ob }}$ mice, the mass increase begins from the age of two weeks, the hyperinsulinemia develops, in four weeks the hyperglycemia manifests itself, the concentration of free glucose in blood continues to grow, achieving the maximum in 3-5 months [9, 105]. The volume of the pancreas significantly increases [9, 106], the hyperlipidaemia progresses, the temperature regulation is disturbed, and the physical activity is reduced $[9,105]$, the infertility develops [9, 107].

In $\mathrm{Lepr}^{\mathrm{db} / \mathrm{db}}$ mice, the autosomal recessive mutation in the leptin receptor takes place $[9,108]$. These mice suffer from hyperphagia, obesity, hyperinsulinemia, and hyperglycemia. The hyperinsulinemia in such mice manifests itself in the age of about two weeks, the obesity from the age of three-four weeks, and the hyperglycemia develops in 4-8 weeks [9].

The Zucker rats possess expressed resistance to insulin that cannot be compensated by the increased level of apoptosis in beta cells [9, 109], which is characterised by hyperinsulinemia at the age of about 8 weeks with subsequent decrease of the insulin level $[9,110]$. The diabetes mellitus in Zucker rats commonly develops in nearly $8-10$ weeks in males, while in females the explicit diabetes does not develop [9, 94]; in these rats the signs of diabetic complications are observed [9, 110].

Depending on the problems under solution, it is necessary to choose for the experimental studies a suitable model of diabetes with the specific features of the models taken into account. Note also that a given model of diabetes could develop in different ways in animals of different lines. Thus, the authors of Ref. [73] obtained different results for outbred and linear mice.

\section{Glycation and non-enzymatic glycation of proteins}

The main complications of the diabetes mellitus disease are related to the glycation of proteins. The glycation is a result of the interaction between the glucose molecules and the proteins, which leads to the change of protein structure and to the restriction of tissue functioning [19, $33-36,38]$. It is known that the protein glycation is initiated by the non-enzymatic reaction between the protein amino group and the carbonyl group of sugar and, correspondingly, leads to the formation of crosslinks between the protein molecules [17, 34, 37]. The glycation results in the Malliard reaction [111113], comprising two stages. As a result of the interaction of protein with glucose via the adducts of the Schiff base, the stable Amadori product is formed. In the course of further incubation, the Amadori product is transformed into an advanced glycation end product [17, 113-115]. The glycation can be accompanied by both the protein modification and the attachment of the advanced glycation end product to the protein receptor [70]. The collagen glycation mechanisms involve complex processes, accompanying the occurring reactions [34, 37, 114, 116, 117]. Such end products of glycation as $\mathrm{N}(\varepsilon)$-carboximetillysine (CML) and pentosidine are known to accumulate in the skin collagen with age and diabetes mellitus. Pentosidine is a fluorescent molecule; it can be detected using the methods of fluorescence analysis $[37,70,114,116,118$ 121]. Glucosepane related to nephropathic, retinopathic, and neuropathic complications [82, 120, 121], glyoxal [118], and pyrroline [70], are also known as advanced glycation end products, as well as other products of glycation and the substances, facilitating their accumulation [70, 121].

Since proteins comprise a considerable part of many tissues, their glycation leads to the change of the tissue structure, the restriction of tissue functioning [6, 34-38, $70,118]$, the metabolic disbalance and, finally, the organ malfunction [17]. Due to the fact that the structure of biological tissues determines their optical properties, it becomes possible to monitor these changes by optical methods, such as fluorescence spectroscopy [34, 36, 42, $79,84-87,116,118,119,122-128]$, refractometry [35, 122], Raman spectroscopy [43, 44, 129], spectrophotometry in a wide range of wavelengths [39$41,47,84,86,130-132]$, electron microscopy [18, 73, 78], laser speckle-contrast imaging [45, 46], laser Doppler flowmetry $[38,84-86,133]$, confocal microscopy [80] and optoacoustic spectroscopy [56].

To study the glycation of proteins, both the samples of tissues and cells from the objects with natural or artificially induced diabetes mellitus (in vivo glycation), as well as the samples that has been glycated under in vitro conditions are used. Studies of in vitro glycation refer, for example, to human placental type IV collagen, performed by fluorescence analysis, as well as by electrophoresis and densitometry [134]; collagen of bovine skin - using multiphoton microscopy [34]; hemoglobin - by optical coherent tomography [135137], refractometry and IR spectroscopy [122], as well as biochemical analysis [138]; albumin - using fluorescence spectroscopy [70], refractometry [122], and terahertz spectroscopy [138]; collagen of the tendon - through biochemical and biomechanical analyzes [139], as well as to collagen hydrogels - using multispectral fluorescence life time imaging (FLIM) [140]; by incubation in ribose [37, 134, 139, 140], glucose $[70,122,135,138,141]$ or fructose $[70,141]$ solutions. All of them show a sufficiently effective glycation of proteins during 10-11 days of incubation, a change in the mechanical properties of tissues due to the formation of collagen cross-links. In work [82], an increase in the glucosapane content in the skin with age and with the development of hyperglycemia in patients with type 1 diabetes mellitus was recorded. 
To determine the degree of glycation of proteins, the studies of the fluorescent properties of the glycated hemoglobin and different tissues [34, 36, 42, 116, 118, 119, 123-127] have been performed earlier. The vascular walls modified as a result of glycation [142], the refractive properties of erythrocytes in healthy volunteers and patients with diabetes mellitus [35], and the optical properties of skin in patients suffering from diabetes mellitus [38, 126, 127] were investigated. Multiple papers are devoted to the development of methods for monitoring diabetes and its different complications, based on the detected changes of the optical properties in diabetic tissues in comparison with healthy ones $[6,17,34-38,41,48,77]$.

After eight months of glycation of the rabbit Achilles tendon in ribose solution [139] the increased maximum load, deformation stress, Young modulus of elasticity, and viscosity, indicating the fact that the glycation increases the stiffness of the tendon matrix, were observed. The tendon glycation was found to lead to significant reduction of the soluble collagen content and considerable increase of insoluble collagen and pentosidine content. Thus, the obtained results show that the collagen crosslinks caused by glycation directly increase the stiffness of the matrix and change other mechanical properties of the tendon.

The analysis of literature shows that the study of glycated biological tissues is a demanded and promising field of research in view of developing novel technologies for noninvasive or low-invasive monitoring of hard complications, their prevention, and treatment maintenance

\section{Optical and structural properties of biological tissues}

\subsection{Blood and cardiovascular system}

The development of diabetes mellitus is related to increased risk of micro- and macrovascular complications (angiopathy) [8, 9, 13, 19, 62-64, 82], such as retinopathy that leads to blindness $[8,9,10,13$, $31,60]$, neuropathy $[8,9,13,60]$, and nephropathy $[8$, $9,13,60]$. Diabetes mellitus considerably enhances the risk of vascular diseases that finally result in the cerebral stroke $[13,19,60,63]$. The hyperglycemia accelerates the atherosclerotic processes [13, 61, 63], the atherosclerosis and the corresponding loss of elasticity of coronary artery walls cause stenosis and, therefore, reduce the blood supply to the cardiac muscle, which finally leads to angina pectoris, cardiomyopathy, and increased risk of myocardial infarction [12, 13, 63, 64]. These serious complications are due to the glycation of proteins in vascular walls permanently washed by blood in the presence of increased free glucose content in blood [41, 129, 135, 138].

Different methods are used to determine glycated hemoglobin or albumin, such as ion exchange, affine, or liquid chromatography, electrophoresis, colorimetric and immunochemical methods [70, 143]. First, these methods are invasive, since they imply blood sampling from the patient's vein. Since the mean lifetime of erythrocytes amounts to three months, it is possible to get information on the glycation accumulated during three months only. Moreover, the accuracy of the measurement is affected by the increased concentration of bilirubin, glucose, lipids, and other substances [143]. Also, the level of free glucose in the blood is influenced by external factors, for example, such as eating and exercise, which limits the applicability of many diagnostic methods where blood measurements are required [7, 8], so it is necessary to develop new algorithms for processing measurement results reducing the influence of external factors.

Optical methods of diagnosing the condition of biological tissues are widely used in biology and medicine, e.g., for determination of oxygenation degree and blood perfusion [144, 145]. The safety of these methods and the possibility to get information in real time explain their wide usage and permanent expansion of the application field in medicine [20, 38, 48, 146149]. Using optical radiation one can also extract information on the structure, composition, and properties of biological tissues, investigate metabolic processes avoiding negative effect on them [144]. An essential advantage of visible and near-infrared optical radiation is its capability of sufficiently deep penetration into biological tissues. The range from 600 to $2500 \mathrm{~nm}$ includes four "transparency windows", i.e., the regions where the light attenuation by biological tissues is minimal. Since many biological tissues contain a lot of water, the spectral transparency windows correspond to the wavelengths, at which the light absorption by water is minimal. The first transparency window includes the wavelengths from 650 to $950 \mathrm{~nm}$, for which the absorption of light by water is relatively weak, but the absorption by hemoglobin and myoglobin is present. The second transparency window is located between two maxima of water absorption and corresponds to the wavelengths from 1100 to $1350 \mathrm{~nm}$. The third transparency window lies in the range from 1600 to $1870 \mathrm{~nm}$ and the fourth window from 2100 to $2300 \mathrm{~nm}$, which is convenient for probing the collagen-containing tissues [145, 150-152].

To assess the degree of hemoglobin glycation the Raman spectroscopy can be used [129]. In Ref. [35], microscopic studies with the Nomarsky interference microscope, combining a two-beam interferometer and a polarization microscope to enhance the contrast of phase images, showed a significant difference in the refractive properties of erythrocytes in healthy and diabetic patients.

In Ref. [41], the quantitative assessment of the glycated hemoglobin concentration in human blood was performed using the spectral analysis in the infrared wavelength range (from 780 to $2498 \mathrm{~nm}$ ). The authors of Ref. [42] measured the fluorescence of blood plasma in 12 days after the alloxan injection to rats. It was shown that the shape of the fluorescence band at the excitation wavelength $320 \mathrm{~nm}$ is most indicative for 
hyperglycemia in the blood plasma samples due to the formation of protein fluorescent link by non-enzymatic glycation. In Ref. [122], the optical properties of hemoglobin and albumin in aqueous solutions of glucose were studied. With the increase of glucose concentration in the solution, the authors observed the increase of the refractive index and the reduction of the absorption in the studied solutions, probably due to the protein-glucose binding. A decrease in the albumin absorbance in the terahertz range of wavelengths was observed with an increase in the incubation time of albumin (glycation in vitro) in solutions of glucose and fructose [138]. Also in this work, slow glycation in glucose in comparison with fructose and the dependence of albumin glycation rate on the $\mathrm{pH}$ of the sugar solution were obtained.

The authors of Ref. [44] have shown the applicability of Raman spectroscopy to the assessment of glycated hemoglobin in vivo with the measurements performed on hand, ear and forehead. Using the Raman spectroscopy, the porphyrin conformations in erythrocyte hemoglobin were revealed in patients with diabetes mellitus [43]. Using the electronic paramagnetic resonance spectroscopy, the reduction of the erythrocyte membrane viscosity was found in patients with diabetes mellitus. The change of permeability was fixed in the plasmatic membrane of the erythrocyte, namely, the higher rate of $\mathrm{Na}-\mathrm{H}$ exchange, the activity of $\mathrm{Ca}^{2+}$-dependent $\mathrm{K}^{+}$-channels, the reduction of the Ca-ATPase activity in patients suffering from type II diabetes mellitus [43]. It was supposed that the change of viscosity and permeability of the erythrocyte plasmatic membrane could be the cause of the conformation change of the hemoglobin porphyrin, the reduction of binding activity and oxygen transport by hemoglobin under the conditions of diabetes mellitus [43].

In the patent [130], a noninvasive method and a device for assessing the content of glycated hemoglobin were proposed based on measuring the light reflection spectra from the studied blood sample. The device consists of two measuring units, one of which contains a spectrophotometer, recording the absorption spectra, and the other one contains a Raman spectrometer.

The possibility to use the absorption spectroscopy method for the assessment of the amount of glycated hemoglobin in the spectral range $200-850 \mathrm{~nm}$ was demonstrated in [131]. Good correlation between the results of spectroscopic method and the standard method of high-efficiency liquid chromatography was obtained.

The method of quantitative analysis of the content of glycated hemoglobin in human hemolysate samples using near infrared (NIR) spectroscopy and the subsequent processing of the spectra by the movingwindow-partial-least-squares (MWPLS) method was proposed in [132]. The method allows to find the optimal wavelength ranges for determining the content of glycated and non-glycated hemoglobin. The optimal wavelengths for the analysis were in the over-current range of the NIR band and were from 958 to $1036 \mathrm{~nm}$ for hemoglobin and from 1492 to $1858 \mathrm{~nm}$ for glycated hemoglobin.

In [153], the optical characteristics of diabetic erythrocytes using a three-dimensional quantitative phase imaging based on Common-Path Diffraction Optical Tomography (cDOT) were noninvasively studied. The morphological (volume, surface area and sphericity), biochemical (concentration and hemoglobin content) and mechanical (membrane fluctuations) parameters of individual cells were quantitatively determined from the measured three-dimensional tomograms for the refractive index and two-dimensional time-dependent phase images. As a result, statistically significant changes in morphological and biochemical parameters of diabetic erythrocytes were not obtained in comparison with nondiabetic, however, the deformability of the membrane of diabetic erythrocytes was shown to be lower.

Since in the case of diabetes mellitus the advanced glycation end products are dissolved in the blood plasma, they interact with the endothelium, affect the endothelium functioning, and cause the accompanying tissue hypoperfusion and hypoxia $[63,114]$. In this way, the advanced glycation end products accumulate in vascular walls, i.e., the formation of crosslinks in the vascular walls occurs [114]. In turn, the endothelium damage gives rise to the development of atherosclerosis $[13,114,142]$. In the presence of diabetes mellitus, the risk of ischemia increases [64, 81].

In comparison with the hemoglobin, which is subject to glycation only during 3 months, the glycation of other proteins occurs during a long time; therefore, the diagnostics of such proteins can provide more information on the condition of the organism in the process of diabetes mellitus development.

In Ref. [73], basing on the histological sections stained by the lectin antibody, the exhaustion of lectin content in the endothelium of mice with four-week streptozotocin-induced diabetes was reported (Fig. 2). The perfusion recovery after ischemia was poorer in diabetic outbred mice (WT) than in linear mice (RAGE KO). Thus, the result can depend on particular animals under study. The studies [81] of human atrium samples in vitro performed after reoxygenation and perfusion that modelled ischemia revealed the cell apoptosis and necrosis stronger expressed in patients with type I and type II diabetes mellitus. In rats with streptozotocininduced diabetes, the apoptosis of myocardial cells was also observed [74].

Diabetes mellitus disturbs the mechanisms of reperfusion, i.e., the activation of earlier existing arterial collaterals and generation of new vessels (arteriogenesis, angiogenesis), thus hampering the recovery after an ischemic stroke $[63,64]$. The development of diabetes in outbred mice [73] was found to cause the smaller number of vessels and the accumulation of the advanced glycation end product in muscles and blood of all mice with diabetes. 

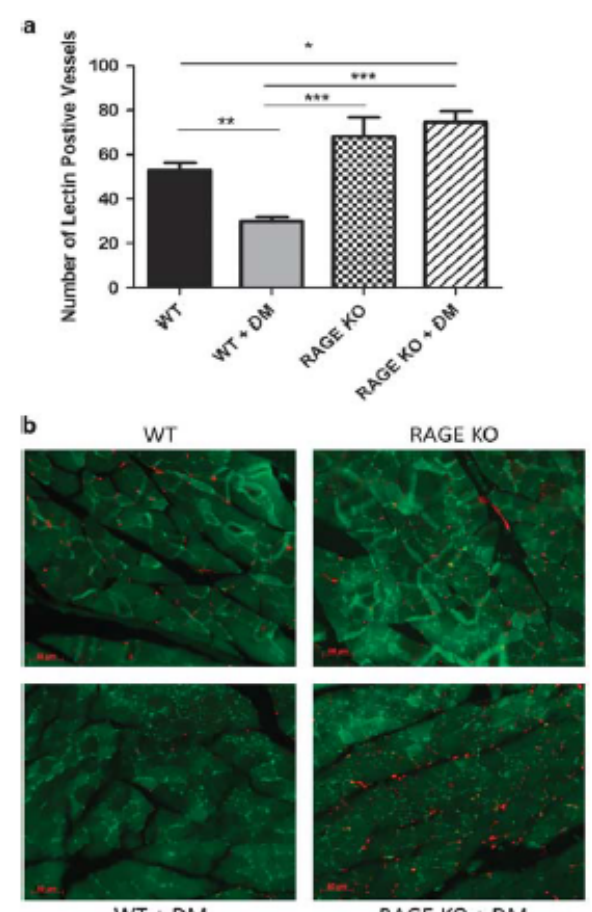

WT + DM

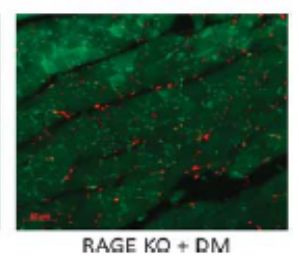

Fig. 2 Histogram (a) and images of histological sections (b) reflecting the content of lectin (red) in WT and WT+DM outbred mice of the control and diabetic groups, and in RAGE $\mathrm{KO}$ and RAGE $\mathrm{KO}+\mathrm{DM}$ linear mice of the control and diabetic groups, respectively [73].

Because of the change of the vessel structure, its physical properties also change. In Ref. [45], the effect of the iohexol solution (X-ray contrast solution, Omnipaque $^{\circledR}$ ) on the blood flow velocity in rats with alloxan-induced diabetes was studied using the laser speckle contrast imaging. In contrast to the control group, in diabetic rats the increase of blood flow rate was fixed, which could indicate the increased endothelial permeability under the development of alloxan-induced diabetes [45]. Using ultrasound to measure the elastic modulus of arteries, the authors showed that under type II diabetes mellitus the elasticity of arterial walls decreases [63, 154]. By means of laser Doppler flowmetry, the reduced blood flow rate was observed in the case of diabetes mellitus [38, 133]. Anomalous thickening of vascular walls in skin was also found [38].

The studies aimed at assessing the noradrenalin effect on the blood flow in mice with alloxan-induced diabetes were carried out [45]. Using the laser speckle contrast imaging, the reduction of venous and arterial blood flow caused by the noradrenalin injection was observed in mice with two- and four-week alloxaninduced diabetes without subsequent restoration of blood flow after the noradrenalin injection (Fig. 3).

Since heart is the main organ of the cardiovascular system, through which the process of blood circulation is implemented in the entire organism, it directly experiences the negative effect of the disease with numerous complications [12, 13, 63, 64]. In Ref. [12], the change of adipocytes and the excess accumulation of lipids on the heart epicardium in patients with diabetes mellitus was reported. Such changes enhance the development of heart diseases. In optical measurements [40], the reduction of the glycerol diffusion rate in ex vivo myocardium of rats with alloxan-induced diabetes mellitus was observed, which indicates the change of cardiac muscle tissue in the very first weeks of the development of alloxan-induced diabetes in rats.

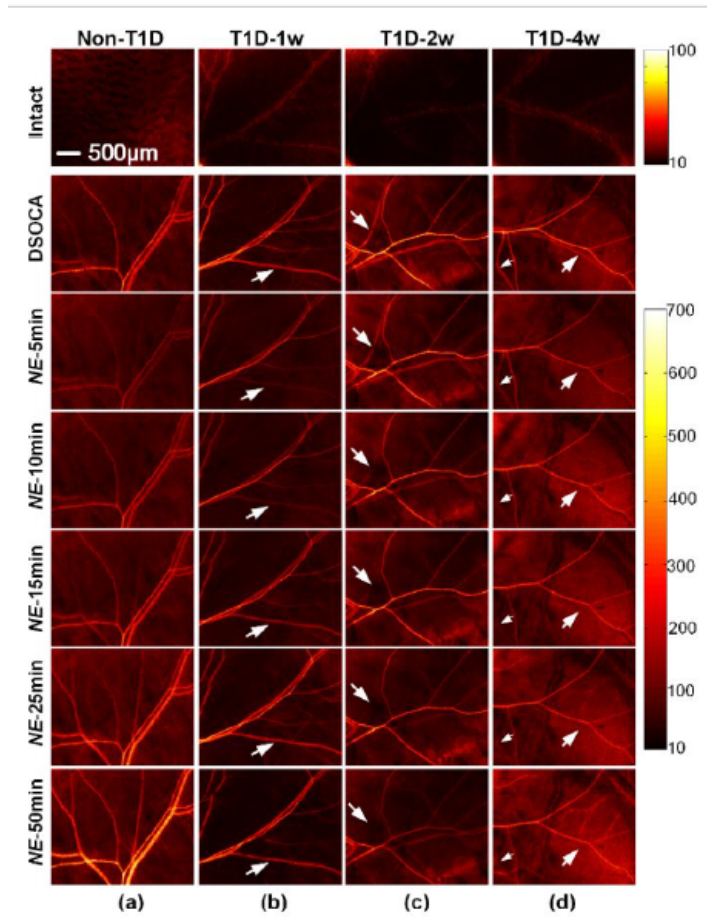

Fig. 3 Typical images of vascular blood flow after the noradrenalin injection to the control group of mice "non-T1D" (a), the mice with one-week "T1D-1w" (b), two-week "T1D-2w" (c), and three-week "T1D-4w" (d) diabetes [45].

The possibility of assessing the functional condition of the microcirculatory system in patients with diabetes mellitus using such optical noninvasive methods as the laser Doppler flowmetry, the diffuse reflection spectroscopy, and the fluorescence spectroscopy was demonstrated in Refs. [84, 86]. The obtained data have shown that the combined application of these three diagnostic technologies allows for revealing and prognosis the development of trophic disorders and the diabetic foot syndrome at earlier stages. The use of wavelet analysis for evaluating the regulatory mechanisms of peripheral blood flow during the heat tests makes it possible to study the changes in the vascular tonus autoregulation and the regulation of bypass blood flow by the sympathic fibers. This allows for indirect consideration of the blood flow innervation and can indicate the presence of neuropathies [84]. The authors of Ref. [86] stated that the hemoglobin introduces a considerable contribution to the spectra of diffuse reflection of human skin in the visible and near- 

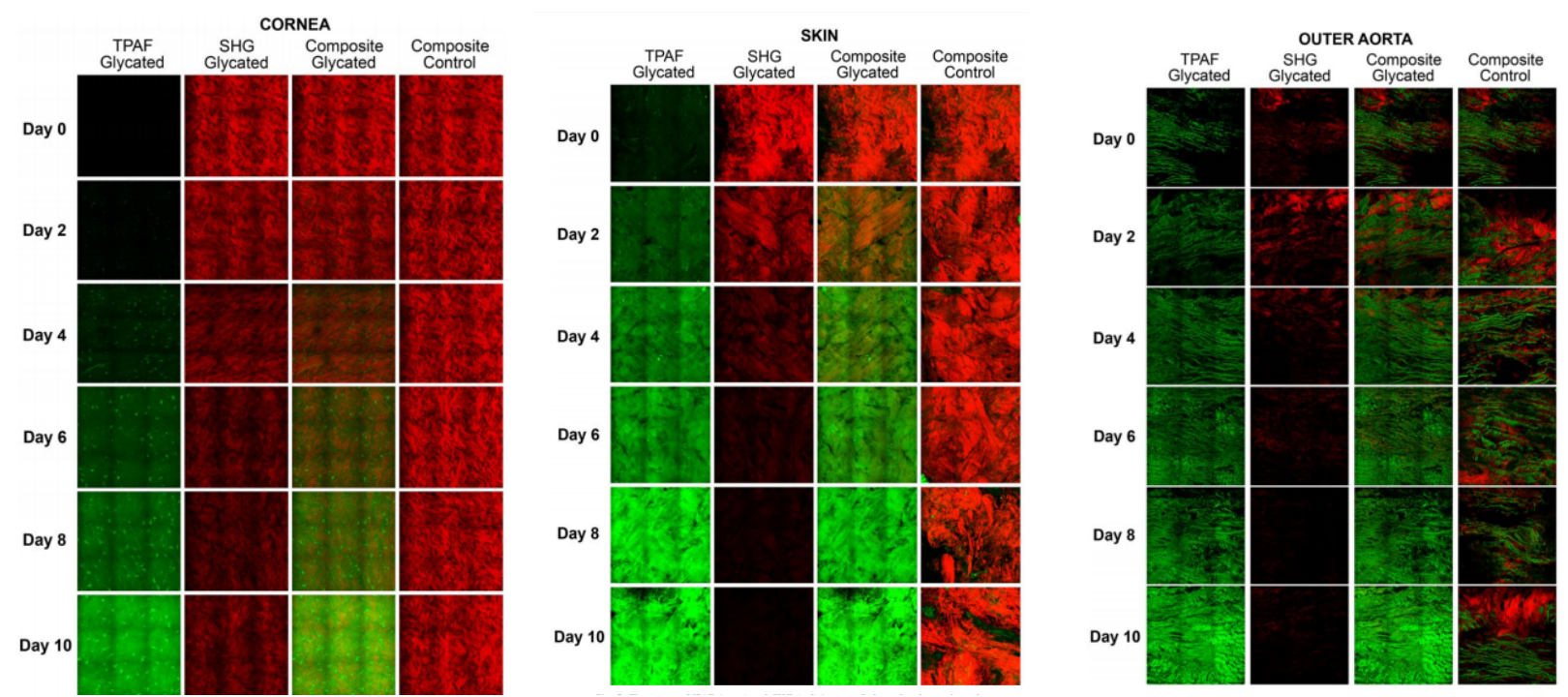

Fig. 4 Images of glycated and control samples of bovine cornea, skin, and outer surface of aorta, obtained by means of multiphoton autofluorescence (green) and the second harmonic generation (red); "Composite" means two superimposed images: the autofluorescence one (green) and the second harmonic generation one (red). The laser wavelength is $700 \mathrm{~nm}$ and the power is $180 \mathrm{~mW}$, the image size is $620 \times 620 \mu \mathrm{m}^{2}$ [34].

infrared range. The variation of its content under the impairments in the microcirculatory layer of the foot skin due to the diabetic microangiopathy can be seen in the reflection spectra as the change of absorption and scattering properties of skin.

\subsection{Different tissues}

Type I diabetes mellitus develops due to the pancreas malfunction that leads to the chronical hyperglycemia and then to the excess glucose in the interstitial fluid disturbing the metabolism and the functioning of many organs $[2,5-11,17,57,65-67,89,92]$. Since all vital organs, such as myocardium, eye retina, and cerebral tissues are abundantly supplied with blood and, therefore, glucose, in the patients with diabetes mellitus they are glycated first.

To find new efficient methods of the diabetes mellitus diagnostics and treatment, to prevent serious complications of this disease, multiple studies of the effect of diabetes mellitus on different properties and functioning of biological tissues and organs have been carried out.

For example, in 12 days after the intra-abdominal injection of streptozotocin to rats [76] the swelling of liver and pancreas mitochondria was fixed that led to the damage of mitochondria and ATP deficiency. In Ref. [17], the effect of diabetes mellitus on the rat internals was studied. After the intra-abdominal injection of alloxan to the rats, the hyperglycemia, polydipsia, and polyuria were fixed in the animals. On the 15-th day after the alloxan injection, the histological sections of liver, kidney, spleen, and pancreas tissues were taken. After the analysis of the histological sections of the tissues, the morphological changes of different degree of severity in comparison with the control group of animals were revealed in the tissues. In the liver, the authors found significant decrease in the glycogen accumulation, in the pancreas the perivascular fibrous indurations were noted, the size and the number of pancreatic islands was decreased [17]. These results confirm the fact that within the frameworks of the alloxan-induced diabetes model in rats already in two weeks after the intra-abdominal injection of alloxan one can detect structural changes of tissues and organs caused by the accumulation of glycogen. In kidneys, the necrosis of individual cells with the development of diabetes was revealed.

Since the high level of blood glucose leads to the growth of its content in the interstitial fluid, the glycation affects not only the blood proteins, such as albumin and hemoglobin [70, 129, 135, 138, 155], but also other proteins of the organism tissues. For example, in Refs. [58, 156] it was concluded that the glycation of collagen under diabetes mellitus facilitates the development of fibrosis. In turn, the structural changes of tissue proteins lead to the change of their optical properties.

Based on the studies of the fluorescence properties of the advanced glycation end products of hemoglobin, skin, cornea, aorta, articular tendon [34, 36, 116, 118, $119,124,157]$, and the corresponding changes in the nonlinear susceptibility of the tissue structures [34, 123, 158], it was found that the glycation facilitates the increase of the tissue fluorescence intensity [34, 116, $118,119,124,125,157]$ and the decrease of the second harmonic generation intensity [34, 123, 158] (Fig. 4).

The authors of Ref. [79] studied the autofluorescence of skin and the condition of brain in vivo in patients with type II diabetes mellitus. The 

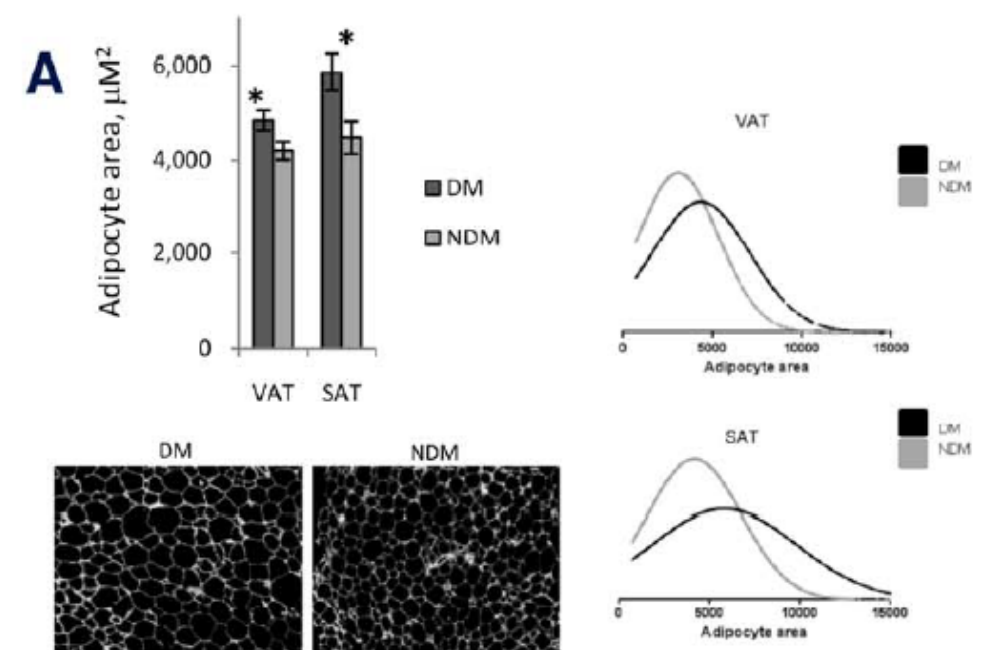

Fig. 5 Histogram, microscopic images, and plots describing the increased size of adipocytes of the visceral (VAT) and subcutaneous (SAT) adipose tissue of the patients suffering from diabetes mellitus [87].

autofluorescence was found to grow both with age and with the development of diabetes mellitus. Using the magnetic resonance tomography (MRT) in patients with diabetes mellitus the reduction of the grey matter in the brain was observed, which, in turn, causes cognitive defects of different degree.

In Ref. [80], it was found that in the group of patients with recently diagnosed type II diabetes mellitus the length and density of nerve fibers is significantly smaller than in the control group. Such studies have been performed by means of the skin biopsy and confocal microscopy of the eye cornea, for which the loss of nerve fibers and the accompanying injure of nerve conductivity were observed, indicating the early parallel involvement of both small and large nerve fibers into the pathological changes.

In turn, the damage of nerve fibers (neuropathy) can lead to a neuropathic foot ulcer, the most severe skin injure arising when the reduced recovery capability of diabetic skin gives rise to infection, formation of gangrene, and, finally, leads to the amputation of lower extremities [58, 59]. The authors of Ref. [79] proposed a hypothesis that the autofluorescence of skin can reflect the formation of advanced glycation end products of other cell proteins, e.g., in neurons.

Since proteins are the main components of many tissues, the glycation of proteins leads to significant change of the tissues structure [34, 37]. The permeability of a tissue for chemical agents is largely determined by the tissue structure and its changes caused by pathological processes, such as glycation. Therefore, the change of the agent diffusion rate in a tissue during a certain time interval can reflect the change of the tissue structure and, thus, can be used as a biomarker of the glycation degree [40, 95, 159]. The study of permeability of biological tissues for different agents is aimed at extracting information on the mechanisms of interaction of tissues with different chemicals, on the transport of drugs in tissues, on the effect of the agents on the optical, diffusion, morphological, and functional properties of biological tissues [48, 49, 52, 146, 147, 160-162]. These data are necessary for efficient application of different pharmacological preparations to treat diabetes mellitus and for developing noninvasive optical methods of disease diagnostics and monitoring [48, 163], since efficiency of treatment (diagnostics) is determined by drug (agent) diffusion rate, i.e., the time during which the drug (agent) molecules reach the target part of the organism.

The slower diffusion of glucose in the kidney sample of diabetic mouse as compared to non-diabetic one was obtained in Ref. [47]. It was assumed that the diabetic kidney has a denser structure at the expense of the tissue glycation. The efficiency of the optical clearing of skin, kidney, and cornea samples in the terahertz wavelength range was higher for non-diabetic samples than for the diabetic ones at application of glycerol solution of different concentration [47].

About $80 \%$ glucose in the organism is transported to muscles [19]. The reduction of insulin production under the diabetes mellitus affects the absorption of glucose by muscle cells, which leads to muscle dystrophy and muscle mass reduction [164]. Using electron microscopy, the authors of Ref. [78] observed the 35\% reduction of mitochondria size in patients with obesity and type II diabetes. The enlargement of vacuoles in muscle fibres, the lowering of $\mathrm{NADH}: \mathrm{O}_{2}$ oxydoreductase in patients with type II diabetes was also found. The authors concluded that at type II diabetes mellitus a failure of the bioenergetics capability of the mitochondria of skeletal muscles takes place.

Larger fat cells were observed in patients with diabetes mellitus as compared to the healthy volunteers [83]. It was shown that the main phenotype of white fat tissue in humans without obesity and with type II diabetes mellitus is the hypertrophy of adipocytes, which can affect the inflammation of fat tissue, the 
release of free fatty acids, the deposition of ectopic fat, and the sensitivity to insulin.

In Ref. [87], using a fluorescence microscope it was found that the mean cross section of the fat tissue adipocytes extracted from the patients during surgical operation is higher in patients with diabetes mellitus than in those of the control group (Fig. 5). The reduction of fibrous tissue formation and the increase of adipocyte hypertrophy was also revealed in patients with diabetes mellitus suffering from obesity. The hypertrophy is a cause of the fat tissue malfunction [87].

The revealed changes of the ocular tissues autofluorescence in the patients with type II diabetes mellitus having no signs of diabetic retinopathy evidence in favour of the accumulation of advanced glycation end products in the eye tissues [165].

The studies of air expired by the patients with type II diabetes mellitus, prediabetic patients, and the control group patients revealed a correlation between the insulin sensitivity index $\left(1 / \mathrm{ISI}_{0,120}\right)$ and the content of the isotope ${ }^{13} \mathrm{C}\left(\delta_{\mathrm{DOB}}{ }^{13} \mathrm{C}(\%)\right)$ in the expired air (Fig. 6). This correlation potentially can serve as a marker for noninvasive assessment of both prediabetic condition and the development of type II diabetes mellitus in humans [166]. This marker was implemented by oral intake of ${ }^{13} \mathrm{C}$-labelled D-glucose that is metabolised and produces ${ }^{13} \mathrm{C}$-labelled carbon dioxide $\left({ }^{13} \mathrm{CO}_{2}\right)$, which arrives at the lungs via the blood flow and then is expired [166].

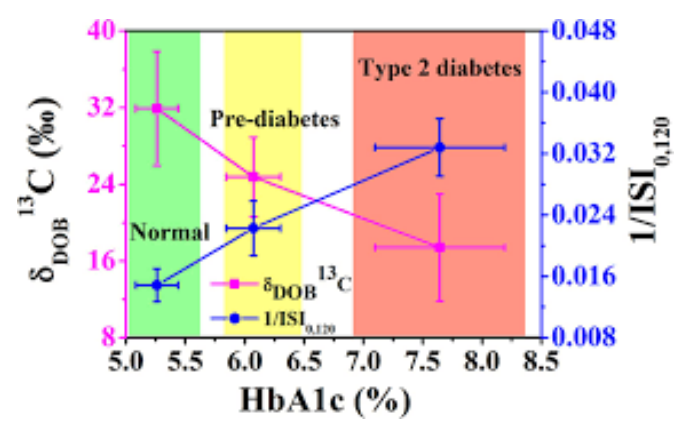

Fig. 6 Distribution of ${ }^{13} \mathrm{C}$ isotope content in the expired air $\left(\delta_{\mathrm{DOB}}{ }^{13} \mathrm{C}(\% \mathrm{o})\right)$ and the insulin sensitivity index $\left(1 / \mathrm{ISI}_{0,120}\right)$ depending on the level of glycated hemoglobin HbAlc (\%) in the blood of the control group (Normal), prediabetic patients (Pre-diabetes), and of the patients with type II diabetes mellitus (Type 2 diabetes) [166].

\subsection{Skin}

With the development of diabetes mellitus, the skin becomes susceptible to various infections, the skin fibrosis is observed, the skin becomes more dry and vulnerable (because of the malfunction of leucocytes), and the patient suffers from skin itch. These symptoms are manifestations of diabetes mellitus complications related to the hyperglycemia and glycation of proteins. There are many skin diseases facilitated by diabetes mellitus [19, 58, 59]. With age, structural changes occur in the skin, such as enlargement of pores, thinning of dermis, loss of bulk collagen, atrophy of blood vessels and flattening of dermis-epidermis junction [167]. These age-related changes are enhanced by the development of diabetes mellitus [63]. The skin fluorescence can reflect the age-related changes, the kidney diseases, as well as the changes induced by smoking [126]. The skin autofluorescence enhancement was observed in diabetic patients with retinopathy and nephropathy [127]. The excitation light wavelength varied from 300 to $420 \mathrm{~nm}$ with the peak excitation at $370 \mathrm{~nm}$. The normalized autofluorescence signal was calculated by division of the mean radiated light intensity in the range $420-600 \mathrm{~nm}$ by the mean intensity of the excitation in the range $300-420 \mathrm{~nm}$ [127].

As can be seen from the works [79, 126], the increase in the fluorescence intensity associated with the development of diabetes, and with the aging, so it is important to distinguish the contribution of age and disease in the results of the study. It was shown in [168] that the number of glycated collagen increased only by $33 \%$ in patients not suffering from diabetes mellitus at the age of 20 to 85 years. While the fluorescence of the final glycation products in diabetics increased five-fold, strongly correlating with age. In patients with diabetes, glycation of collagen increased three-fold compared to non-diabetic subjects, strongly correlating with the content of glycated hemoglobin in the blood, but not with age. Thus, for a certain age, appropriate glycation levels in tissues can be identified. With diabetes, these indicators are significantly increased.

Many papers are devoted to the study of optical and structural parameters of skin in the process of diabetes mellitus development and its modelling. Unfortunately, the conclusions based on different studies are often contradictory [57]. Thus, in Refs. [169, 170] the hydration of stratum corneum was shown to reduce in humans and mice in vivo in the process of diabetes mellitus development, the reduction of water content being not related to the barrier malfunction of epidermis. However, in Refs. [169, 171] it was stated that in the case of diabetes mellitus the transepidermal loss of water does not increase. The authors of Ref. [170] state that long-term hyperglycemia disturbs the barrier function of the skin and its permeability.

In mice with model diabetes mellitus, the reduction of keratinocyte proliferation in epidermis was observed [57, 171, 172], while in Refs. [170, 172] no such changes were observed in the experiments with rats and mice of other age. Contradicting results were also obtained in the studies of epidermis thickness in the case of diabetes [57]. In some papers the authors conclude that the epidermis thickness does not change $[170,172,173]$ under the conditions of long-term hyperglycemia in rats and the diabetes mellitus in humans and mice, however, other authors using other model of diabetes mellitus or animals of other age state that the thickness either decreases [171, 172, 174], or increases [175]. The ultrasonic measurement of skin thickness in patients with diabetes mellitus revealed the skin thickness increase [176]. In Ref. [172], the 

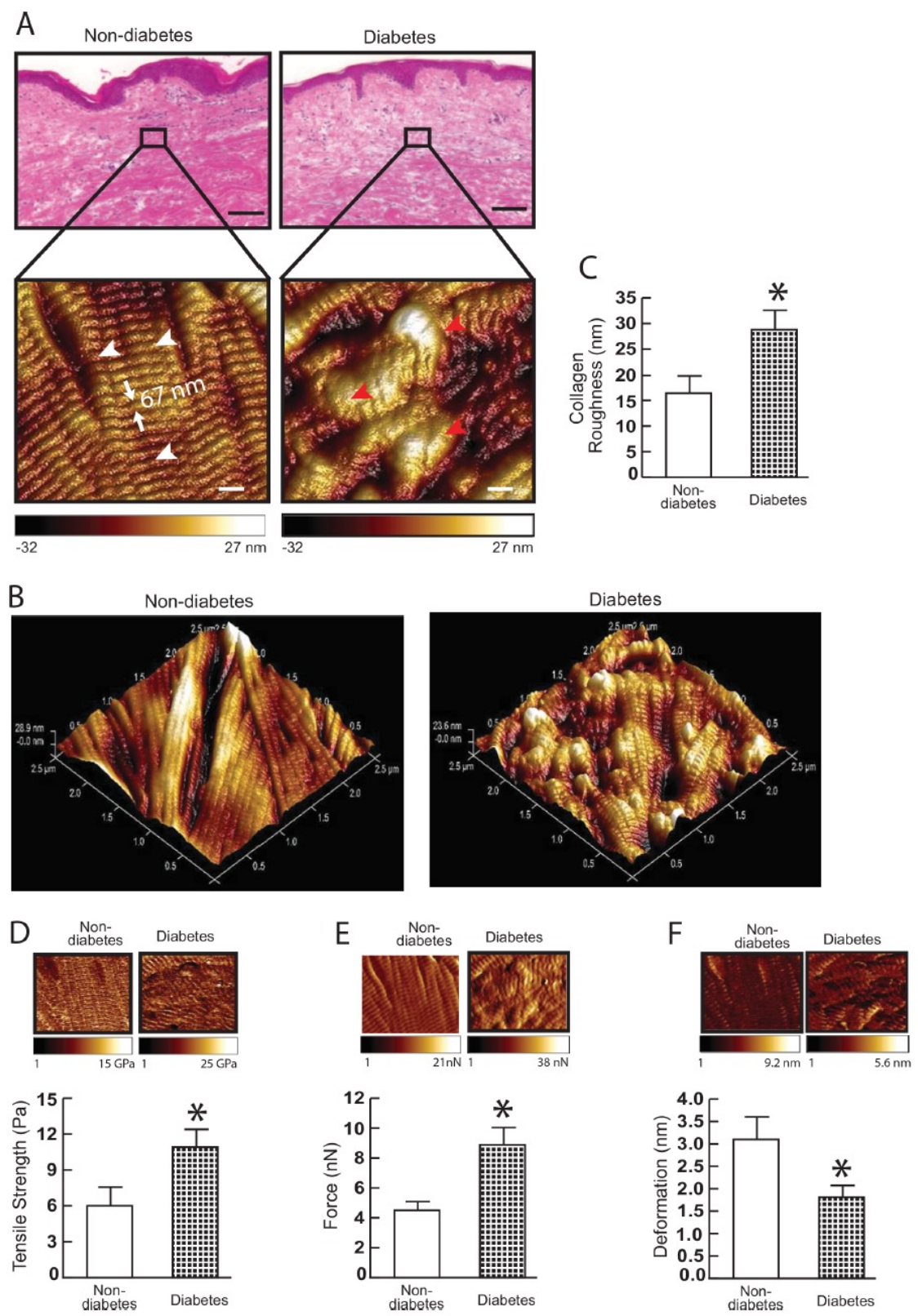

Fig. 7 (A) Image of collagen fibrils obtained using atomic force microscopy (AFM). White and red arrows point at the intact and fragmented/disordered fibrils, respectively. (B) 3D images of collagen fibrils, obtained using the AFM. (C) Roughness of collagen fibrils estimated using the Nanoscope Analysis software (Nanoscope_Analysis_v120R1sr3, Bruker-AXS, Santa Barbara, CA). (D) The tensile strength. (E) The traction force. (F) The deformation of collagen fibrils determined using the AFM PeakForce ${ }^{\mathrm{TM}}$ Quantitative NanoMechanics mode and Nanoscope Analysis software [179].

conclusions could be different due to different age of mice under study. The contradiction of results could be also due to the use of different models of diabetes mellitus. The change of collagen distribution in dermis was observed by means of histology and microscopy in diabetic patients with complications, in contrast to those having no complications [177]. The inconsistent results require checking or specifying the features of the experiment that could cause the contradictions.

The formation of advanced glycation end products reduces the elasticity and solubility of collagen, enhances its stiffness [58, 178]. The results presented in
Ref. [179] confirm that the accumulation of fragmented skin collagen and the presence of molecular crosslinks in the case of diabetes mellitus impairs the structural integrity of skin collagen and its mechanical properties. In the studies of aging diabetic skin, the expressed crosslinks of collagen fibres were demonstrated. The atomic force microscopy (AFM) has shown that in the case of diabetes the collagen fibrils of skin are fragmented and disordered (Fig. 7(A, B)), and the key mechanical properties are essentially changed [179]. The quantitative analysis of AFM data has shown that the mean roughness of collagen fibrils as a measure of 

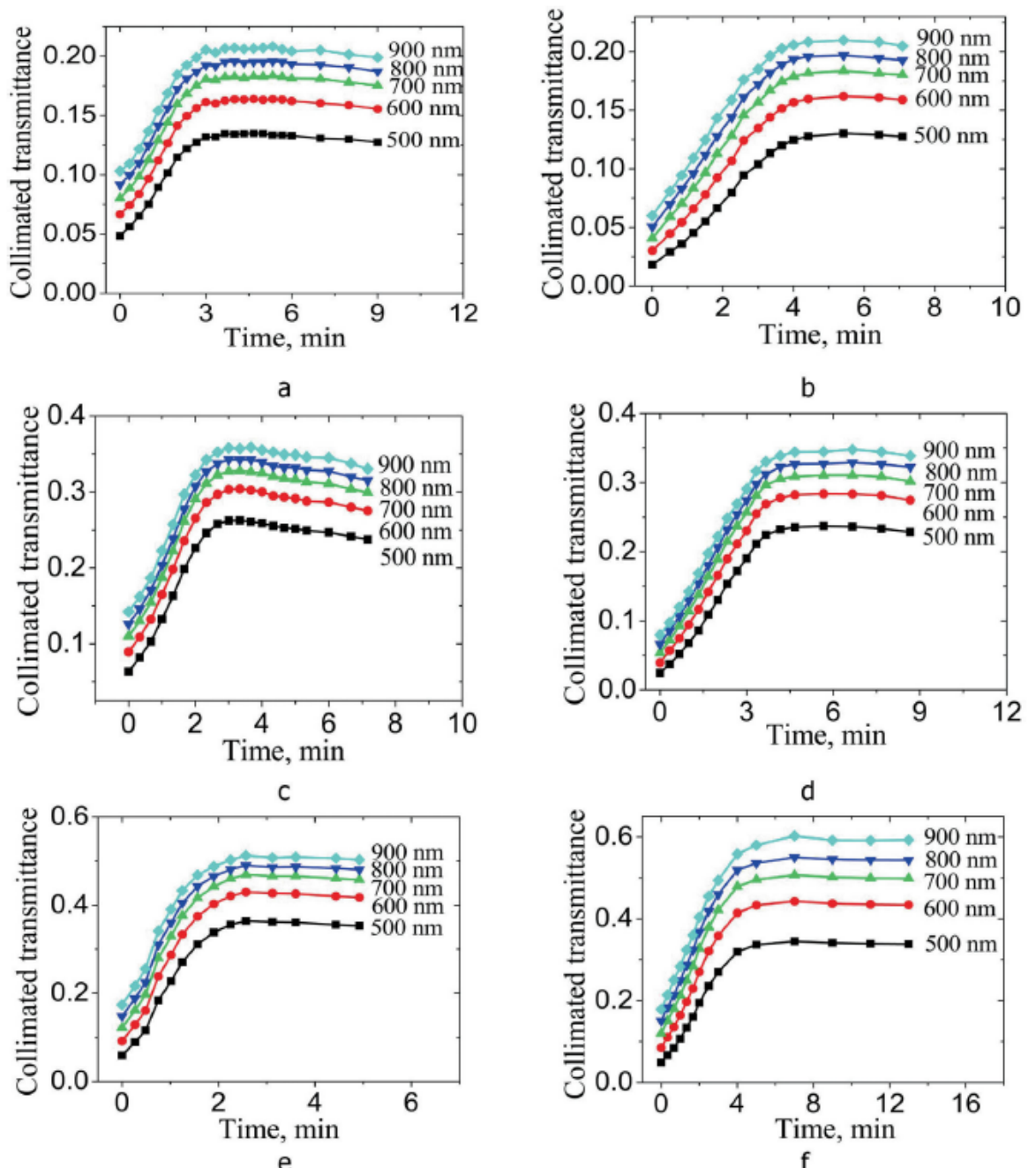

e

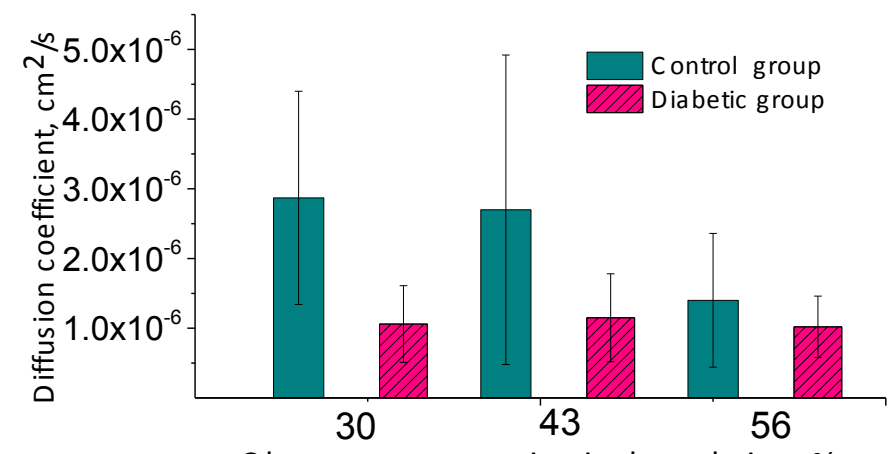

Glucose concentration in the solution, \%

g

Fig. 8 Kinetic curves of optical clearing (a-f) and diffusion coefficients of glucose $(\mathrm{g})$ in the skin of mice of the control group (a, c, e) and diabetic group (b, d, f) obtained with the 30\%- (a, b), 43\%- (c, d), and 56\%- (e, f) solutions of glucose [39].

their arrangement increases in diabetic dermis by $176 \%$ (Fig. 7(C)), from $16 \mathrm{~nm}$ to $29 \mathrm{~nm}$, which can be related to the increased content of matrix metalloproteinases (MMPs) that lead to fragmentation of collagen fibrils. The fragmentation of fibrils impairs the structural integrity of collagen and, thus, changes the mechanical properties of the dermis. The basic mechanical properties, such as the tensile strength (Fig. 7(D)) and traction force (Fig. 7(E)), were found to increase by $197 \%$ and $182 \%$, respectively, while the deformation of collagen fibrils was reduced by $58 \%$ (Fig. $7(\mathrm{~F})$ ) in 
diabetic dermis in comparison with the non-diabetic one.

The mechanical properties of the collagen hydrogel after incubation in solutions of ribose and glutaraldehyde (GTA), which promote the formation of collagen cross-links, were studied in paper [140] using multispectral fluorescence lifetime imaging (FLIM). In the case of collagen incubation in GTA, in contrast to ribose, correlations were observed between the fluorescence lifetime and the mechanical properties of collagen. It has been shown that the nature and degree of collagen cross-links have a significant effect on the elasticity of the tissue also under the action of ribose.

Under the in vitro glycation of murine skin in the glyoxal solution [118] the transepidermal loss of water was increased, the content of saturated fatty acids in the peidermis significantly increased. Moreover, the barrier function of the epidermis was impaired. The skin immersed in the solution of glyoxal acquired a yellow hue. The presence of advanced glycation end products in the skin was detected using autofluorescence, the intensity of which was increased.

Ref. [39] presents the result of studies of glucose diffusion in ex vivo skin of mice with alloxan-induced diabetes mellitus by measuring the collimated transmission of visible light through the skin samples. The glucose diffusion in the skin of mice with alloxaninduced diabetes was found to occur by up to 2.5 times slower in comparison with the control group (Fig. 8). Close results were obtained for the glucose solutions of three different concentrations: $30 \%, 43 \%$ and $56 \%$. Analogous reduction of glycerol diffusion rate was observed in the ex vivo skin samples from rats with alloxan-induced diabetes mellitus [40].

The optoacoustic spectroscopy was used for the study of advanced glycation end products in skin in the case of in vitro glycation [157]. The principle of optoacoustic spectroscopy is based on the transformation of the energy of pulsed or timemodulated optical radiation into thermal and further acoustic waves when interacting with an object, while as a spectrally non-selective detector of absorbed energy at different wavelengths a microphone or an ultrasonic transducer is served [180]. The conditions of physiological hyperglycemia were provided by immersion of porcine skin samples in the ribose solution during 17 days. As a result, the increase of the optoacoustic signal with the incubation time and the maximal absorption of light by the glycated skin in the wavelength range 540-620 nm was observed [157]. Possibly, the increased intensity of the optoacoustic signal with the growth of skin glycation degree is related not only to the high light absorption by glycated skin (in the wavelength range 540-620 nm), but also to the increased efficiency of light-to-sound conversion due to greater tissue elasticity because of the crosslinks between the fibres. In this paper, the increase of fluorescence intensity and the decrease of the second harmonic generation intensity are also demonstrated for the glycated skin (Fig. 9).
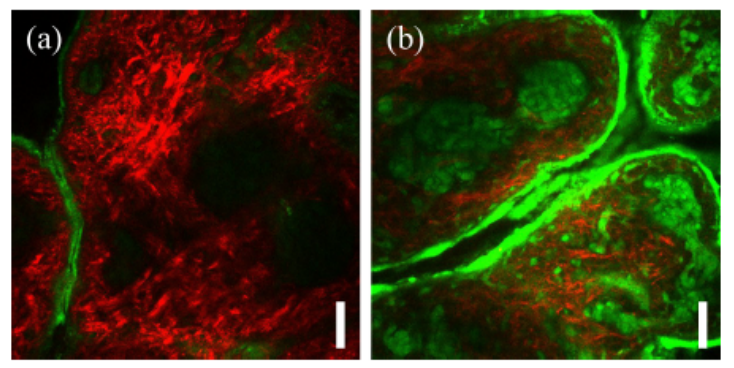

Fig. 9 Microscopic images of porcine skin incubated during 17 days in a) phosphate buffer solution, and b) ribose solution. Superimposed images of autofluorescence (green) and second harmonic (red) intensity are shown. The images were obtained at the depth $35 \mu \mathrm{m}$, the scale bars correspond to $50 \mu \mathrm{m}$ [157].

The patent [128] proposes a device whose operation principle is based on fluorescence, by which it is possible to determine the final products of glycation of collagen, to measure their concentration in skin, the oral mucosa or sclera tissues in order to diagnose diabetes mellitus or pre-diabetic condition. The area of the tissue contactly or contactlessly illuminated by light of wavelengths selected from a wide range, fluorescence of the tissue caused by the exciting radiation is recorded, after that the analyzing system of the device determines the degree of glycation of the tissue from the measured spectral properties.

In Ref. [85], authors evaluated the possibility of combined measurements of skin fluorescence and blood perfusion using the laser Doppler flowmetry for the diagnostics of type II diabetes complications in the lower extremities of the patients. The blood microcirculation was topically stimulated by heating. The experimental studies have shown that the patients with diabetes mellitus demonstrate enhanced fluorescence and lower perfusion response to the local heating, which can play the role of markers for different degrees of diabetic complications.

Ref. [88] describes a method of noninvasive in vivo monitoring of hyperglycemic state in mice with streptozotocin diabetes, based on mm-wave spectroscopy, which has been experimentally confirmed using live animal models as objects. The transmission coefficient of the skin fold at the nape of mice of various lines was measured at 25 uniformly located frequencies in the range $0.075-0.110 \mathrm{THz}$. Skin transmission was several times higher for animals in the hyperglycemic state and depended little on the presence of white or black hair, or its absence in mice.

\section{Conclusion}

The effect of diabetes mellitus development on the biological fluids and tissues is widely studied, and the development of different research techniques additionally stimulates the growing interest to this disease. In view of diagnostics, it is of primary value to detect the earliest changes in the tissues, related to the progress of diabetes mellitus at its initial stage. As can 
be seen from the review, many optical methods are applicable to the diagnostic study and monitoring of the degree of glycation of biological tissues and fluids in the development of diabetes. These include refractometry, Raman spectroscopy, fluorescent spectroscopy, spectrophotometry over a wide range of wavelengths, laser speckle-contrast imaging, laser Doppler flowmetry, optical coherence tomography, confocal microscopy and optoacoustic spectroscopy, multiphoton fluorescence microscopy and harmonic generation. Among a variety of optical methods, one of the promising, because of the simplicity of implementation and the possibility of non-invasive diagnostics, is the fluorescence spectroscopy method, which allows for recording the presence of final glycation products in tissues. Also promising are refractometric and phase methods, including using optical coherence tomography and three-dimensional diffraction tomography. The methods of terahertz spectroscopy and imaging can also be referred to promising methods for studying glycated biological tissues and fluids. The problem of non-invasive monitoring of early structural changes in biological tissues associated with diabetes gradually loses its status as "unresolved".

\section{Disclosures}

All authors declare that there is no conflict of interests in this paper.

\section{Acknowledgment}

The studies were carried out under the support from RFBR grants 18-32-00587 (DKT); 17-00-00275 (17-0000186 (DKT) and 17-00-00272 (VVT)); and 18-5216025 (DKT, VVT). 